\title{
On the (future) role of on-demand insurance: market landscape, business model and customer perception
}

\author{
Angela Zeier Röschmann ${ }^{1}\left[\right.$ [ $\cdot$ Matthias Erny ${ }^{1} \cdot$ Joël Wagner ${ }^{2,3}$ (1)
}

Received: 18 June 2021 / Accepted: 17 January 2022 / Published online: 7 February 2022

(c) The Author(s) 2022

\begin{abstract}
Over the last decade, digitisation and individualisation have fostered the development of on-demand services in many industries. In the insurance sector, technological progress brings new possibilities on how risks can be insured. This paper studies on-demand insurance and thereby takes three perspectives. First, we define on-demand insurance and study the current market landscape of offerings, leading to a characterisation of the phenomenon. Second, we analyse the on-demand insurance business model, discuss how value is created, and develop a taxonomy of the dimensions among business model components. Third, we describe the awareness and interest of potential customers in Switzerland using novel data recorded from a recent consumer survey. Using the results from the market study, business model analysis, and customer survey, we discuss the (future) role of on-demand insurance, shedding light on the ongoing business model transformation in the insurance industry. We conclude that insurtech companies address emerging customer needs and that traditional incumbent insurers must innovate to keep their prominent role at the customer interface. While novelty and complementarity of on-demand insurance solutions bring value today, we expect that efficiency and customer retention will add more value in the future, especially once technology has matured and business model components are well-aligned.
\end{abstract}

Keywords On-demand insurance $\cdot$ Market landscape $\cdot$ Business model $\cdot$ Survey study $\cdot$ Technology innovation $\cdot$ Insurance economics

\section{Introduction}

On-demand services have become popular in various industries (e.g. music, books, video) as well as lately also in insurance. The main reason for the popularity of these examples found in academia and practice is their disruptive impact on traditional

Joël Wagner

joel.wagner@unil.ch

Extended author information available on the last page of the article 
industries. Hence, a critical question for the insurance sector is whether on-demand insurance changes the industry logic in the same way, with new players developing, dominating the market and, ultimately, displacing incumbents.

"The world is on-demand. Your insurance should be, too," is the claim of Slice, an on-demand insurance technology provider. ${ }^{1}$ Early on-demand insurance providers have typically been start-ups such as Trov, Slice, Cuvva, or Lings. These market entrants all use at least some of the digital transformation ingredients, namely digital technology, big data, computing power and data analytics, to provide a fully digital offering (Bauer et al. 2021). Risks covered are associated with an activity such as travelling, driving or short-time work assignments, or sharing items, a flat or equipment. Typically, customers trigger coverage via their smartphone either by manually turning coverage on and off or by allowing some form of automation through data exchange (see Braun and Haas 2019). The value proposition of on-demand insurance rests on flexibility and unbundling: insurance cover can be purchased for risks as needed, at any time of the day and for as long as necessary. The trend toward ondemand insurance is reinforced by a rising interest in instant and usage-based services and products related to lifestyle or new work arrangements (European Insurance and Occupational Pensions Authority, (EIOPA) 2020). While the phenomenon currently is marginal in terms of market share, practice-oriented studies argue that insurers will have to transition to incorporate on-demand insurance in order to remain relevant (KPMG 2017; EIOPA 2018; Tata Consultancy Services 2019).

Current research on the phenomenon is scarce and can mainly be found in the context of insurtech. Insurtech is defined as a "phenomenon comprising innovations of one or more traditional or nontraditional market players exploiting information technology to deliver solutions specific to the insurance industry" (Stoeckli et al. 2018). However, research related to the development of insurtech companies has only yet emerged. Being the most mature connected-device insurance area, it is not a surprise that most current research centers on telematic systems. Many publications focus on questions related to new segmentation and pricing mechanism in telematics (Störmer 2015; Weidner et al. 2017; Wüthrich 2017; Barry and Charpentier 2020; Guillen et al. 2021) or questions related to the risks and benefits of using tracking devices for health insurance and services (Henkel et al. 2018; Wiegard and Breitner 2019). A comprehensive view on the potential and future relevance of ondemand insurance as a future form of insurance is lacking. Currently, the term 'ondemand insurance' is used in many different ways, and it is unclear whether ondemand insurance creates value (Braun and Haas 2019).

In this paper, we address this gap by (a) providing a definition, discussing differences and overlaps with related terms and concepts, and analysing the characteristics of current market offers, (b) studying the business model and the value creation behind it, and (c) surveying the perception of potential customers in Switzerland. This comprehensive overview then allows us to (d) discuss the (future) role of ondemand insurance.

$\overline{1 \text { See https://slice.is (June 2021). }}$

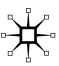


A key part of our research on understanding on-demand insurance is based on a business model perspective. Business model constructs are increasingly used by academics and practitioners to study entrepreneurial innovation, especially related to e-business and the use of information technology (Amit and Zott 2001; Zott et al. 2011; Veit et al. 2014; Pousttchi and Gleiss 2019). Despite conceptual differences among researchers about the definition and components, Zott et al. (2011) identify common research themes. The business model construct emerges as a new unit of analysis that is distinct from product innovation. The approach is holistic in that it seeks to explain how firms do business. It includes partners and the network in the analysis and the interest often lies in understanding value creation and value capture (Zott et al. 2011). Using this viewpoint, we aim to better understand the logic of how on-demand insurance creates value. For that purpose, we focus on the holistic 'gestalt' of the on-demand insurance model and identify the interrelated components. The framework of Foss and Saebi (2017) on business model innovation guides the structure. These authors developed a framework to ensure a systematic and comprehensive analysis of business model innovation and its implications by including antecedents and moderators. Grounding our analysis in their framework mitigates the conceptual ambiguity associated with the young field of business model research.

Our main results are as follows: first, we derive key differentiators of on-demand insurance compared to traditional insurance offerings. A market analysis allows us to distill the main characteristics of on-demand insurance and its providers. On-demand insurance is characterised by instant quotes, narrow coverage, flexible durations, and digital delivery coming through dynamic premium rates with small pay-per-use installments. Second, the business model analysis concludes with a taxonomy of the dimensions among business model components. We find that potential business models are heterogeneous and show the dimensions that must be optimally aligned to create value. Third, our customer survey provides indications on the potential interest in on-demand insurance. Digital literacy, risk-taking, regular travel and a self-oriented 'search and understand' insurance-buying behaviour are factors fostering the potential usage of on-demand insurance. Finally, discussing business model innovation and the (future) role of on-demand insurance, we find that the insurance industry engages in adaptive and focused innovation in contrast to complex business model innovation. We observe that incumbents cannot avoid innovation if they want to keep a role at the interface with their customers. Maturing technology and well-aligned business model components will allow the on-demand value proposition and revenue model to be unlocked.

The paper is organised as follows. In the section 'What is on-demand insurance?', we provide an overview of the background and a definition of on-demand insurance. Further, we present in the section 'Landscape and characteristics of offers' the current market landscape and characterise the offerings. In the section 'Dimensions of the business model', we dimensionalise the components of the on-demand insurance business model, drawing on theoretical considerations and market observations. The awareness and interest of potential customers are discussed on the basis of survey data in the section 'Customer perspectives from a survey in Switzerland'. As a final step, in the section 'Discussion on the future role of on-demand insurance', we 
identify antecedents and moderators to understand the novelty and potential scope of business model innovation when engaging in on-demand insurance. We conclude in the 'Conclusion' section, providing a view on limitations and venues for future research.

\section{What is on-demand insurance?}

The emergence of on-demand insurance is rooted in the overarching trends of digitisation and individualisation. Digitisation not only changes consumer expectations and the way insurance products can be produced and delivered, but also the underlying risks. Cars and homes become smarter and connected, items and homes are less owned and more shared and many workers work on demand in the gig economy. In effect, digitisation changes life and work styles as well as the risks and the way they can be insured. Although customers' habits change, the need for insurance persists. Stoeckli et al. (2018) state that "in a world of increasing uncertainty and dynamics, the economic and social importance of being insured seems undisputed and even gains in importance."

Technological progress and the availability of data provide new possibilities to provide easy and instant access and personalised insurance offerings. Usage- and behaviour-based car insurance, health insurance discounts for tracked healthy lifestyles or on-demand insurance are market examples of this movement. Products, their distribution and promotional offers tend to become more personalised, although issues for insurance pricing arise (McFall and Moor 2018). Indeed, data from wearables and telematics devices allow risks to be quantified more accurately and even dynamically during a contract. This development has given rise to a discourse on discrimination (see, for example, Landes 2015) as so-called 'bad' risks will have to pay a higher premium while 'good' risks profit from discounts or lower premiums (Eling and Lehmann 2018).

On-demand insurance is a relatively new phenomenon. The term is often used interchangeably with usaged-based insurance (KPMG 2017; National Association of Insurance Commissioners 2021). Yet, there are notable differences between these emerging concepts. In usage-based insurance the contractual relationship between insured and insurance company persists continuously, i.e. also in times where the item is not 'in use', because the usage-based insurance component is often part of a traditional insurance coverage. A prominent example is usage-based insurance for cars, where basic liability and theft insurance may be always in force and additional premiums for liability and collision cover are calculated upon usage (e.g. number of kilometres, driving habits). In on-demand insurance, the contract ends when turning insurance off. A customer can choose to turn on insurance from different providers at different moments. The mode of activation can range from manual to automatic (see Table 1): coverage can be activated manually, recommended by a smart device and activated manually by the user, or activated automatically based on criteria like location, activity or context. While this automatic mode of activation might be the future for car or embedded insurance, it does not necessarily extend to all areas of on-demand insurance. Therefore, we conclude that usage-based insurance is 


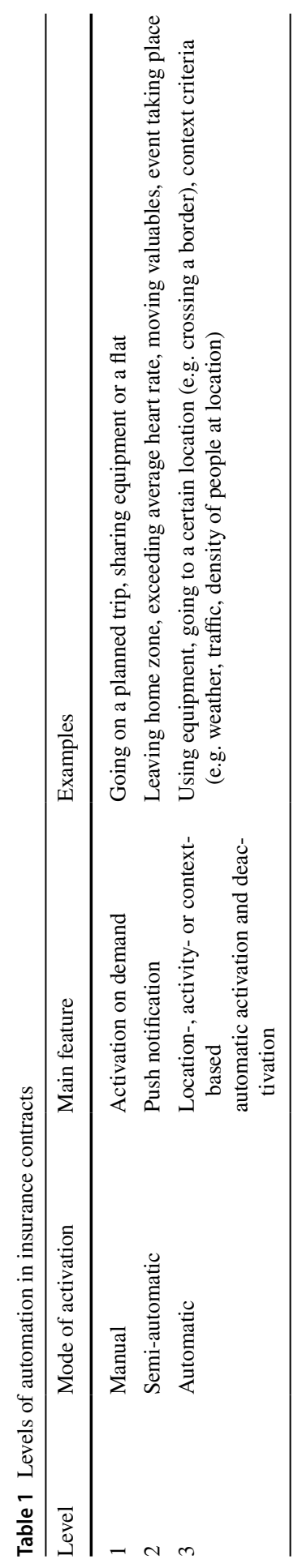


a subcategory of on-demand insurance characterised by an automatic mode of activation (level 3). Moreover, on-demand insurance is currently broader than usagebased insurance as the concept of providing 'coverage as-needed' is extended to other risks, including travel and liability coverage where connectivity is not always provided or difficult or even impossible to achieve. The key concept of on-demand insurance is about timing and duration versus usage.

The key characteristic of on-demand insurance is that consumers can turn coverage on and off as needed. Consumers typically purchase on-demand insurance at or for the moment and for as long as they incur a specific and often higher risk as a consequence of an activity or ownership. In addition to the term on-demand, we find others in the literature that relate to the same context. For example, the term 'episodic' (Golia 2018) is used to describe a product for homeowners to get coverage when sharing their home on AirBnB. Stoeckli et al. (2018) use the term 'situational' to describe an insurance product with "flexible selectable periods of coverage". However, these terms have not yet become established.

The flexible duration of on-demand insurance leads to shorter contract periods compared to the traditional annual insurance period. Further, it is difficult for the insurance company to foresee the contract duration. In the extreme, the possibility of swiping insurance on and off even allows for hourly insurance, hence leading to micro-durations and small premium amounts. Regarding small transactions and a comparatively low premium per transaction, on-demand insurance resembles microinsurance. However, on-demand insurance addresses the needs of a mobile and highly connected population expecting individualisation, while microinsurance addresses low-income segments and typically covers existence-threatening risks, allowing premiums to be paid in small installments (Churchill 2006; Eling et al. 2014).

Associated with the element of timing, we also find the term 'instant' insurance. However, the understanding of its meaning is diverse, ranging from insurance pushed to the consumer for instant take-up (EIOPA 2018), instant understood as different to a conventional contractual period (Riasanow 2020), instant in terms of claim settlement based on blockchain, or smart contracts as found in parametric flight insurance (Lin and Kwon 2020; Martin 2018). While just-in-time production of documentation and automatic claim settlement is a reasonable operational ambition for on-demand insurance, we do not consider it as a defining aspect. The instant initiation and flexible cancellation of insurance coverage at the moment of turning the contract 'on or off', however, is key to its definition.

On-demand insurance is an inherently digital solution. Individuals have the technology-enabled possibility of choosing the duration of coverage, timing, as well as the number of items, events, or people who are covered (Braun and Schreiber 2017). The emergence of on-demand insurance is tightly linked with the proliferation of smart devices, driven by but not restricted to the use of smartphones to organise more and more aspects of life. Against this background, we include the technologydriven context in the definition of on-demand insurance.

In conclusion, we define on-demand insurance as a technology-enabled phenomenon of instantly purchasing insurance for a manually chosen or technology-triggered duration covering risk exposures arising from an activity or ownership. The 
Table 2 Comparison of traditional insurance and on-demand insurance

\begin{tabular}{lll}
\hline & Traditional insurance & On-demand insurance \\
\hline $\begin{array}{lll}\text { Duration to quote } \\
\text { Scope of coverage }\end{array}$ & $\begin{array}{l}\text { Ranges from instant to days } \\
\text { Wide, based on status or ownership } \\
\text { (e.g. bundles of items, activities or } \\
\text { events) }\end{array}$ & $\begin{array}{c}\text { Instant } \\
\text { Narrow, based on activity or owner- } \\
\text { ship } \\
\text { (e.g. single items, activities or events) }\end{array}$ \\
$\begin{array}{ll}\text { Puration } \\
\text { Distribution and delivery }\end{array}$ & $\begin{array}{l}\text { Brick \& mortar, agent, paper, digital } \\
\text { Payment mode }\end{array}$ & $\begin{array}{l}\text { Flexible take-up and cancellation } \\
\text { Digital only }\end{array}$ \\
Premium rate & Static (based on ex ante information) & $\begin{array}{l}\text { Pay-per-use } \\
\text { Dynamic (e.g. daily rate) }\end{array}$ \\
& with large installments & with small installments \\
\hline
\end{tabular}

definition includes both the timing and duration as well as the personalisation of coverage in a technology-driven context. Table 2 summarises the key differences between on-demand insurance and traditional insurance offerings considering the criteria given by Rejda and McNamara (2017) and Wagner (2017).

\section{Landscape and characteristics of offers}

To study the characteristics of on-demand insurance offerings, we conducted webbased market research in May and June 2021. We used the search string (('ondemand' OR 'instant' OR 'situational' OR 'episodic' OR 'temporary') AND 'insurance'). In this way, we identified a number of offerings worldwide with an 'on-demand' claim. We report the results in Table $3 .^{2}$ We only include those offers that meet our definition of on-demand insurance (see the 'What is on-demand insurance?' section) and focus on insurtech companies with standalone offers versus incumbents because their business model components are more observable. For each result, we document the name of the on-demand product or brand name under which it is offered and the name of the company. We also record the country of origin, acknowledging that some companies offer their products internationally. A short description of the product and classification of the risks covered is based on

\footnotetext{
${ }^{2}$ Sources of information for Tables 3 and $4:{ }^{a}$ https://www.airsurety.com, bhttps://www.buddyinsurance. com, ${ }^{c}$ https://www.oekk.ch/en/private-clients/offering/other-insurance/short-term-insurance, ${ }^{\mathrm{d}} \mathrm{https} / / /$ www.insureandgo.com, ${ }^{\mathrm{e}} \mathrm{https}: / / \mathrm{www}$. tuneprotect.com/travel-easy-insurance, ${ }^{\mathrm{f}} \mathrm{https} / / / \mathrm{www}$. tuneprotect. com/products/sports, ${ }^{g}$ https://www.cuvva.com, ${ }^{\mathrm{h}}$ https://www.veyygo.com, ${ }^{\mathrm{i}} \mathrm{https}: / / \mathrm{www}$.dayinsure.com, ${ }^{10} \mathrm{https}: / / \mathrm{www}$.insuredaily.co.uk, ${ }^{\mathrm{k}} \mathrm{https}: / / \mathrm{www} \cdot$ digitalblanket.com, ${ }^{1} \mathrm{https}: / / \mathrm{www} \cdot c o m m a . i n s u r e,{ }^{\mathrm{m}} \mathrm{https}: / /$ www.domcura-ag.de/index.php/reisegepaeckversicherung.html, ${ }^{n}$ https://www.friendsurance.de, ${ }^{\circ} \mathrm{https} / / /$ www.klinc.com, ${ }^{\mathrm{P} h t t p s: / / w w w . l i n g s . c h, ~}{ }^{4} h t t p s: / / w w w . d u u o . c a / r e n t-m y-s t u f f-i n s u r a n c e,{ }^{r}$ https://www. duuo.ca/gig-insurance, ${ }^{\mathrm{s}} \mathrm{https}: / / \mathrm{www} \cdot$ thimble.com, ${ }^{\mathrm{t}} \mathrm{https} / / / \mathrm{www} \cdot$ bind.com, ${ }^{\mathrm{u}} \mathrm{https} / / / \mathrm{www} \cdot$ demandoo. com, ${ }^{\mathrm{v} h t t p s: / / w w w . o m o c o m . i n s u r a n c e, ~}{ }^{\mathrm{w}} \mathrm{https}: / / \mathrm{www}$.slice.is, ${ }^{\mathrm{x}} \mathrm{https}: / / \mathrm{www}$. sureapp.com, ${ }^{\mathrm{y}} \mathrm{https}: / / \mathrm{www}$. trov.com. Information retrieved in May and June 2021.
} 


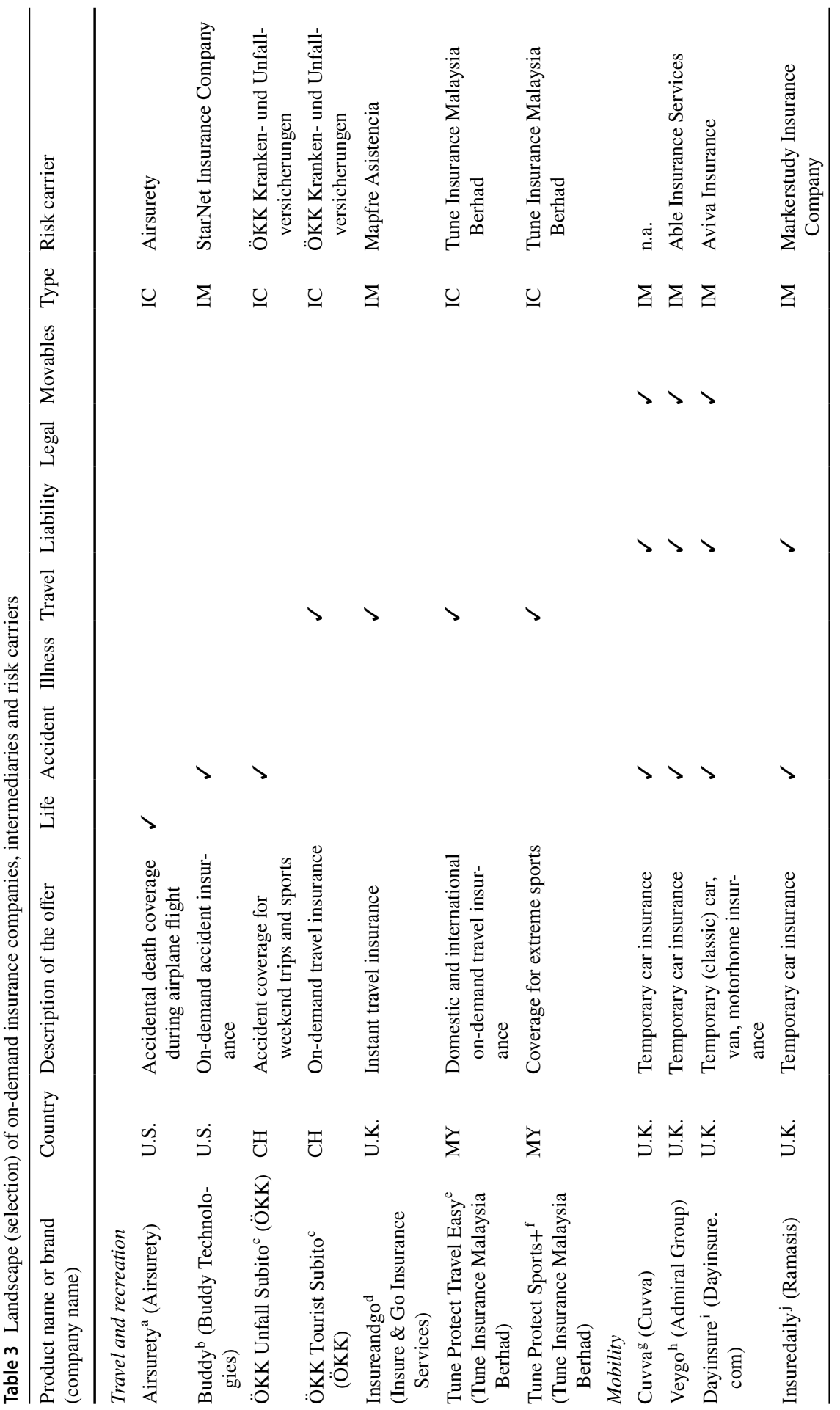

s. 


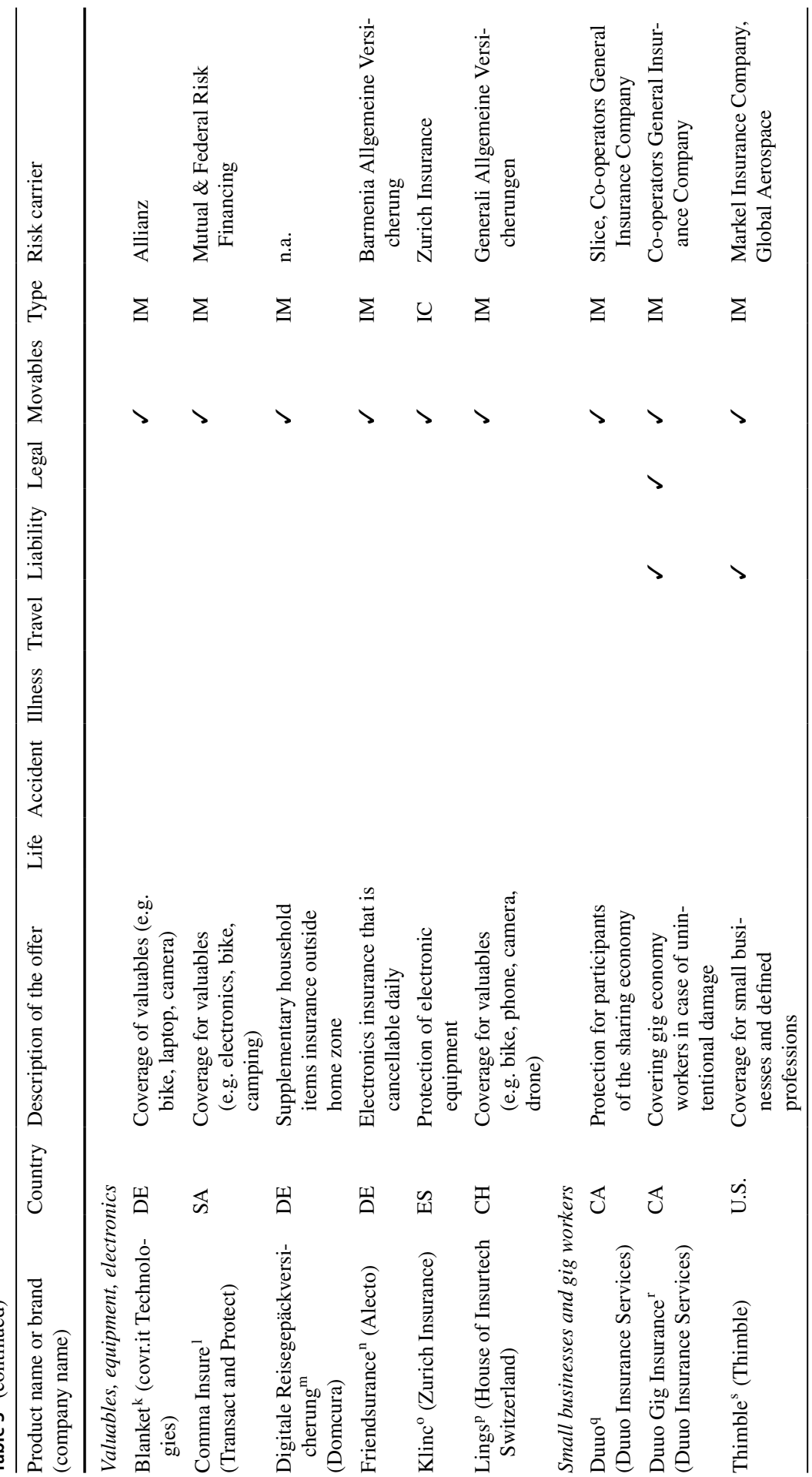




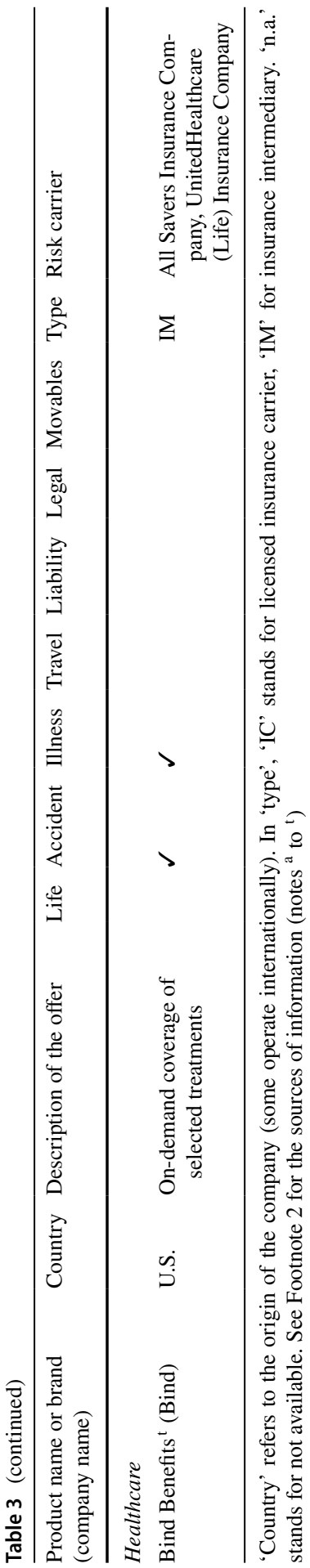

站。 


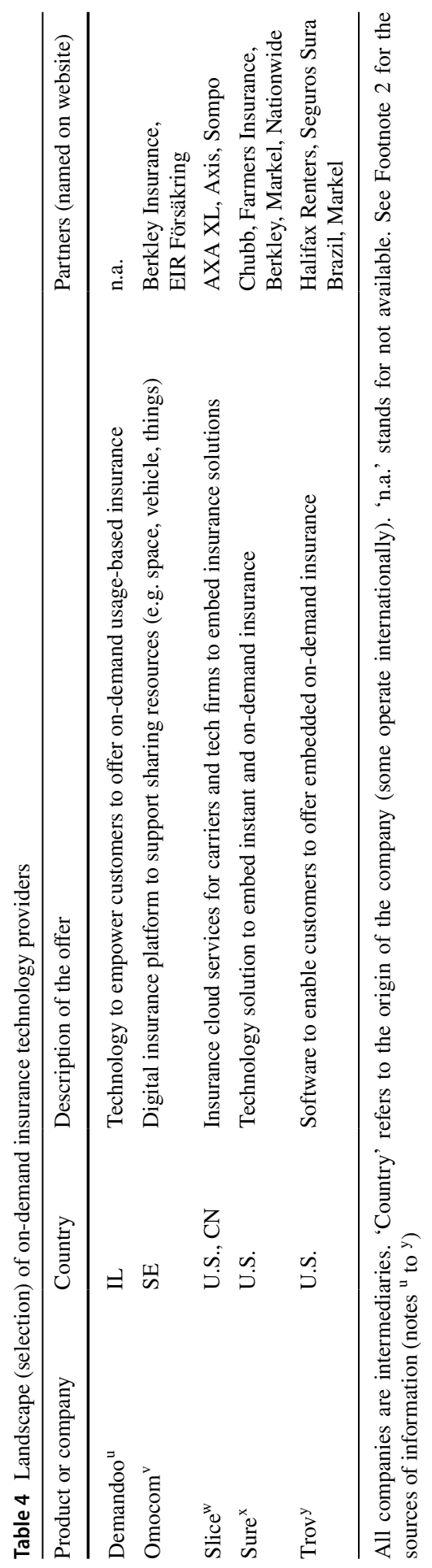


information found on the companies' websites and in the terms and conditions of the product if these were publicly available.

We identified a selection of on-demand insurance offerings in relation to travel and recreational activities, mobility, movable items or equipment, small business activities as well as healthcare. It is not a surprise to find travel insurance in our market overview as it perfectly fits the on-demand concept due to its time-related nature. Additionally, we find offers that target travelling recreationists, e.g. adventurers or amateur sportspeople. Note that our list only reflects a selection of offers.

With respect to (new forms of) mobility, we find various usage-based offers such as Metromile or Voom that do not offer contracts that can be taken out or cancelled on demand. This is why they do not appear in Table 3. In the U.K., a range of products propose temporary car insurance (e.g. Cuvva, Admiral Group, Dayinsure, Insuredaily).

With respect to insurance for movable goods, we find several offers related to ownership, lending and rental of valuables, equipment or electronics. These offers have in common that they cover a specific movable item against damage or theft for the chosen or triggered period. Compared to traditional household insurance, they often include extended coverage, such as theft outside the home, zero deductible or a higher replacement value. Even though some offers do not use the term 'on-demand' in their market appearance, we qualify them as on-demand given their instant takeup and flexible cancellation feature.

We further identify on-demand insurance offers for small businesses and gig economy workers. These address the fluctuating need for liability and other types of coverage that the self-employed and gig economy workers face due to variable work assignments. While there are temporary health insurance offers, such as ERV guest insurance or EHealth insurance for transitional periods, we only retain one ondemand offer for the coverage of selected health treatments.

It is interesting to observe that some early movers such as Trov, Slice and Sure have evolved into insurance technology providers. We list them in Table 4. Both Trov and Sure initially started covering movable items on demand. They now focus on enabling others, namely carriers, tech firms, platforms or retailers, to provide ondemand insurance embedded in their own service offerings.

Our market review also reveals that many on-demand insurance providers, especially insurtech companies, only act as intermediaries. Thereby, the risk carrier is an insurance or reinsurance company providing capital, underwriting capabilities and the necessary license (EIOPA 2020). The advantage of intermediaries is that they can focus on one step in the value chain, that is organising coverage and access according to the changing work and lifestyles of customers. Additionally, in comparison to incumbent insurers with infrastructure legacies (Eling and Lehmann 2018), insurtech companies tend to portray greater agility in relation to testing and implementing new technologies and products (EIOPA 2020). Against this background, we observe insurtech and technology providers as organising the 'face to the customer' for on-demand offers. However, we also observe that some incumbent insurers mirror insurtech companies with their own digital brands (such as Zurich Insurance with Klinc). Finally, let us note that we do not list sharing and rental platforms, travel agencies and other companies that embed some kind of (on-demand) 


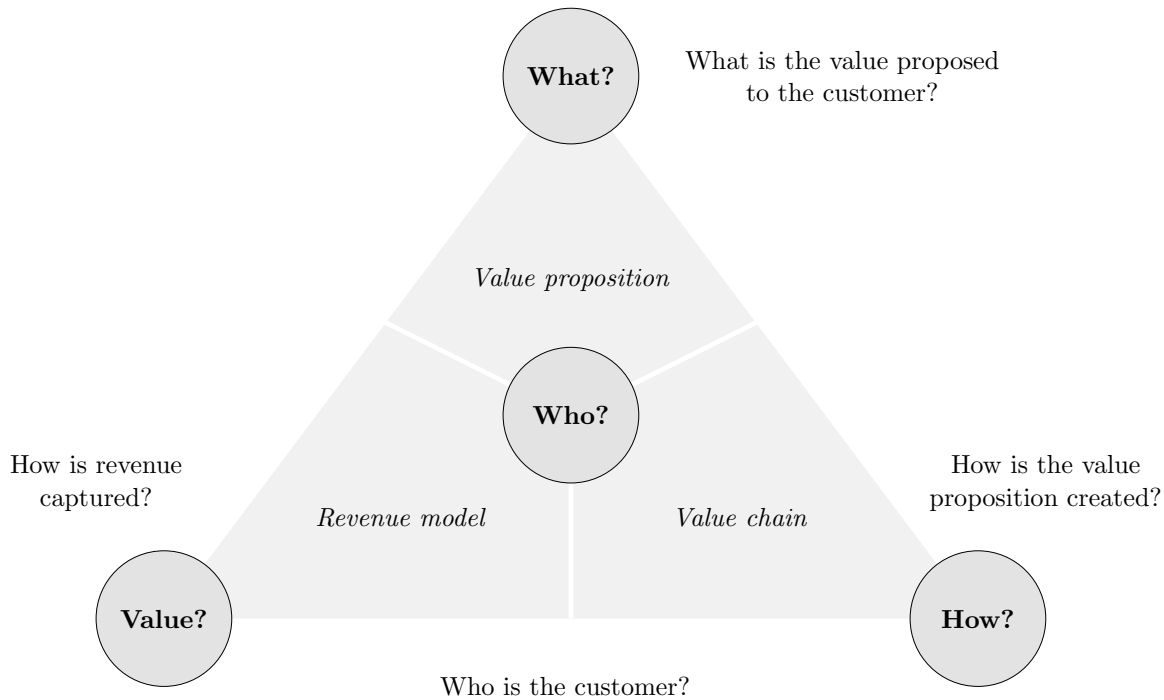

Fig. 1 Definition and components of a business model (adapted from Gassmann et al. 2020, p. 7)

insurance as part of their service package as they presumably source insurance solutions from firms listed in Tables 3 and 4 .

\section{Dimensions of the business model}

To capture the heterogeneity and scope of on-demand insurance with respect to value creation, we identify the business model along the typical components and dimensions (see, e.g. Foss and Saebi 2017). Even though different definitions of and approaches to studying business models exist, the most commonly mentioned components are value proposition, value creation and value appropriation (Osterwalder et al. 2005; Teece 2010; Foss and Saebi 2017; Gassmann et al. 2017). In the sequel, we chose to describe the business model of on-demand insurance using the concept of Gassmann et al. (2017), as it is high-level, takes a holistic view, originates from the study of innovative business models and has been used earlier to study digital transformation (Gassmann and Sutter 2019) and insurtech business models (Braun and Schreiber 2017; Zwack et al. 2016). Gassmann et al. (2020) ask four overarching questions to describe a business model (see Fig. 1): Who is the customer? What is the value proposed to the customer? How is the value proposition created? How is revenue captured? In the following sections, we answer these questions in regard to on-demand insurance.

\section{Who is the customer?}

The landscape of current market offers reveals that typical target customers of ondemand insurance are occasional travellers and recreationists, low-frequency car 
drivers, sharing economy participants and gig economy or self-employed workers (see Table 3 in the 'Landscape and characteristics of offers' section).

\section{Segments}

Target customer groups centre around activities, lifestyles or new work and ownership models that traditional insurance contracts do not well reflect regarding instant on-demand take-up, flexible duration, and coverage. Traditional insurance contracts are often annual in terms of period and cover a risk such as death, accident, liability or property damage. From the perspective of the target customer groups, the activity or ownership does not justify the costs of buying an annual insurance policy for these risks. Also, the quote and binding processes of traditional insurance products do not match the insurance needs that come with weekend trips, renting out equipment for a day or short-term work assignments. On-demand insurance arguably reflects the needs and risk profiles of these target customers more closely (EIOPA, 2020).

Similar to what is observed in usage-based insurance (KPMG 2017; Tata Consultancy Services 2019), millennials and digital affine customers are the most interested. Our survey among retail customers in Switzerland provides additional evidence (see Table 8 in the 'Customer perspectives from a survey in Switzerland' section). Current on-demand providers (Table 3) address both retail, self-employed and small-sized enterprises. Large companies already have access to tailor-made coverage and services such as Internet of Things-based fleet insurance solutions, so they do not appear (yet) as a target segment of on-demand insurance. Potential customers do not necessarily need to be insurance customers but can also be users of mobility, health, smart home or other services (Stöckli et al. 2019). Consumers can be offered on-demand insurance as a complementary and embedded offer at a point of need (e.g. a point of sale). Points of sale are targeted by insurance technology providers that provide insurance platforms (see Table 2). Hence, potential buyers of ondemand insurance can simply be participants in a digital ecosystem (Keller 2018).

\section{Risk profile}

It is controversial whether on-demand insurance offers attract customers with a riskier profile or, in other terms, whether on-demand insurance customers portray a different loss distribution (see the 'How is revenue captured?' section). Our survey results outline that those intending to use on-demand insurance are also more likely to take financial risks (Table 8). Hence, the results provide some evidence of the existence of adverse selection. However, against the background that the delivery of on-demand insurance is typically data-driven, and some products are even sensorbased, information asymmetry can be argued to decrease as the use of technology powering on-demand offers matures. This would allow insurers to charge higher premiums to individuals who present higher risks. Such differentiation would, in theory, drive out high-risk individuals as premiums for them would skyrocket. 


\section{What is the value proposed to the customer?}

The value proposition rests on differentiation, both with respect to simplicity (instant, digital) and flexibility (anytime on and off). In consequence, the proposition yields individualisation of coverage and price. Stoeckli et al. (2018) identifies "simplicity, flexibility, and customer centricity" to be a common value proposition among insurtech innovations. According to KPMG (2017), on-demand insurance customers "can feel confident that they have the protection they need, while only paying when that coverage is actually required."

\section{Size of premium}

As the coverage period is typically short, premiums are small. However, EIOPA (2020) found in a recent market survey that a daily motor insurance policy in the U.K. was approximately $50 \%$ more expensive over a 'working year' compared to the average premium of an annual motor insurance policy. Although using ondemand insurance may be more expensive overall, customers are able to pay premiums in small installments.

\section{Convenience}

The purchase process is typically fully digitised via a smartphone app or digital platform to provide a frictionless and convenient experience (Stanczyk 2018). Moreover, the process is paperless and customers receive instant or on-demand confirmation of insurance. In the event of a claim, the process presumably becomes more complicated when it is delivered by the respective risk carrier. While the main content of the policy is summarised on the website for the convenience of the customer, the details are specified in terms and conditions that resemble traditional insurance policies in their language and length (see also the 'Landscape and characteristics of offers' section). Moreover, the degree of convenience also depends on the mode of activation outlined in Table 1. Indeed, there is a risk that customers forget to turn off manually activated coverage.

\section{Personalisation}

In their market appearance, on-demand insurance providers address specific consumer needs. Coverage reflects a momentary or situational need (e.g. usage of a flat or a shared item, work assignment, travelling, learner drivers) or selective or niche needs (e.g. valuables insufficiently covered when taken outside the house, sport activity insufficiently covered by basic accident insurance). Hence, on-demand insurance is not only about personalising the price, it also provides unbundled insurance coverage to address specific needs. 


\section{Transparency}

Giving customers more control with flexible and unbundled insurance coverage is a less obvious part of the value proposition. The apparent simplicity of the contract and processes contribute to the feeling of control, as Thimble advertises "change, pause, or cancel your policy instantly, with no wait and no hidden fees. Call the shots, not the 1-800". ${ }^{3}$ However, while we find that respondents of our survey (Table 7) perceive on-demand insurance as a more flexible and modern solution, they do not consider it as particularly more transparent than standard insurance policies on a yearly contract basis. Nevertheless, customers are able to more transparently track the costs of each coverage period.

\section{Additional services}

On-demand insurance providers are in a position to add more value beyond financial protection by leveraging digital processes and data. Such data-driven added value ranges from providing consumers insights into their individual risk profile and providing recommendations for risk-mitigating behaviour (Stöckli et al. 2019) to advice regarding insurance coverage (Roberts et al. 2020). If certain data are exchanged in real time, the provider can furthermore identify momentary needs based, for example, on geolocation (EIOPA 2020). While information from data "improves risk assessment and transfer, it creates the potential to predict and prevent risks, as well as offer wider insurance coverage" (The Geneva Association 2021, p. 6).

\section{Gamification}

Schmeiser (2018) notes that gamification is another added value not to be underestimated. Many consumers show interest in playful elements such as photographing loved items and planning trips ahead of time. Allowing them to turn coverage on and off, be it for just a few moments, adds a playful element to the concept of insurance. Stöckli et al. (2019) also mention the possibility to compare oneself with others (e.g. through an illustrated risk profile in a smartphone app) as a potentially playful element.

\section{How is the value proposition created?}

A central aspect of the value proposition is the promise to easily and instantly provide a quote and proof of coverage for a specified risk. Hence, digital access and delivery of on-demand insurance are key.

3 See https://www.thimble.com (June 2021).

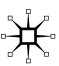




\section{Use of Internet of Things technology}

Driven by the value proposition but also dependent on digital capabilities, the usage degree of Internet of Things technology and automation varies among ondemand insurers with regard to coverage activation, loss detection and loss payment. Considering car insurance, Lamberti et al. (2018) outline an on-demand car insurance as a combination of "block-chain technology and sensors installed on a vehicle to (1) semi-automatically modify car insurance coverage, (2) certify a coverage's activation/deactivation, and (3) attest to a vehicle's status at a given time" (p. 73). They argue that blockchain and smart contracting would also enable the provision of on-demand insurance for smart homes. Further technologies that are frequently cited as enablers of on-demand insurance are machine-learning and image-processing technologies (Tata Consultancy Services 2019).

\section{Limits to automation}

The potential for automation further depends on the access to risk-relevant data, the frequency of data exchange and the willingness of customers to collect and share data about a person's or object's location, activity and usage or context and environment. Smartphones, wearables and installed devices are among the most frequently used mobile technologies to collect data for insurance (EIOPA 2018, 2020; Lamberti et al. 2018; Stanczyk 2018; Wiegard and Breitner 2019). Furthermore, data collected from social media could enable digital transformation (Fitzgerald et al. 2013). For example, posts on social media platforms about the latest adventure trip could flow into the risk scores of customers (Stanczyk 2018) and lead to differentiated instant pricing.

Undoubtedly, (embedded mobile) technology is a key enabler of on-demand insurance. While coverage activation and loss notification can also be initiated manually by customers (e.g. on-off button, uploading pictures) or semi-automatically based on a push notification by a smartphone (see Table 1), embedded technology has the benefit of disburdening customers from thinking about insurance coverage or having to file for a loss, to reduce the risk of fraud and save operational expenses.

\section{How is revenue captured?}

The logic to capture value in business is based on transferring inputs into profitable outputs. The economics of insurance rests on pooling similar risk from individual insureds, charging premiums in exchange for coverage, and reinvesting the premium income in interest-generating assets. Thereby, the collected premiums throughout the portfolio and the investment income must cover the total expected losses of the portfolio plus all related expenses. Hence, broadly speaking, when insurers accept a specific risk of a customer, the price that is charged is based on the cost of adding that risk to the portfolio. In traditional insurance pricing schemes, the premium depends on a set of a priori information provided by the insured, such as age, type 
of vehicle, value of object, amount of income and so on. Uncertainty regarding pricing and reserving factors is typically met by adding loadings to the premium or by reducing the risk with deductibles, coverage limits and exclusions in the contract wording. However, the scope for such actions is limited in the case of on-demand insurance given its small premium installments, reflecting micro-coverage and micro-duration, and a value proposition of simple and convenient processes. Simultaneously, risk assessment becomes more granular and pricing more personalised and dynamic. In the following we discuss some aspects that challenge the economics of insurance.

\section{Underwriting (pricing)}

Actuarial rate making is one of the key activities in insurance. While the number and size of claims is uncertain, describing potential claims and forecasting liabilities is within the focus (Zweifel and Eisen 2012). Individual risks are typically gathered in cohorts sharing similar characteristics. However, in the context of on-demand insurance, shorter and unforeseeable contract durations make it difficult to build cohorts for calculating premiums, a process that traditionally assumes a yearly contract basis. Indeed, individual and ex ante unknown contract durations make it quasi-impossible to forecast the underlying liability in time. This challenge can be compared to the one that appears in other areas at the crossroads of insurance underwriting and the development of technology. For example, as technologies related to the Internet of Things increase the amount of available data and information, more accurate risk profiles become available, the view on risks becomes more precise, risk pools turn out to be smaller and homogeneous cohorts are more difficult to form (Barry and Charpentier 2020). In that line of reasoning, many usage-based insurance models face similar challenges. Although calculating adequate premiums in the underwriting process is more difficult, short contracts have the advantage that they open the possibility of continuous underwriting. Premiums can be dynamically adapted each time the customer seeks coverage. Hence, the contract wording and the price (experience pricing) can be adjusted at each activation taking into account newly available information or adverse development. Finally, the 'denomination effect' also plays a role in small premium amounts (Schmeiser 2018). Customers' price elasticity is typically lower in the micropayments required for on-demand insurance. Hence, one can expect that higher percentage-based loadings are possible in on-demand contracts compared to the overall larger payments in traditional contracts.

\section{Information asymmetry and moral hazard}

Since the coverage of risks is only sought for by customers in prevision of specific (more risky) times, the information asymmetry and adverse selection effects need to be reviewed. In fact, consumers have private information on the risks they take and adapt the frequency with which they demand cover. Contrariwise to traditional insurance policies where high- and low-risk periods alternate, mean risk levels in on-demand insurance are high during times when insurance cover is active. Assuming that customers have an information advantage regarding their risk, at least in 
terms of the timing of the exposure, by activating the cover, they provide insurers with information about their risk exposure or preferences (Schmeiser 2018). Following this idea of self-selection, most recently, Braun et al. (2020) analyse the potential of on-demand insurance as a screening device. Building on the classic models of Wilson (1977), Miyazaki (1977) and Spence (1978), they confirm that the known market equilibria are altered since low-frequency users keep away from standard policies while receiving better coverage (see also Braun and Haas 2019). A study by the Vereinigung der Bayerischen Wirtschaft (2017) questions the assumption that insureds know their risk profile better than insurers. Indeed, information asymmetry might reverse in on-demand insurance where insurers could better assess their customers' risks through digital technologies. Although the resulting prices would be fairer, some existing customers might want to avoid on-demand or usage-based policies because they fear revealing their (poor) risk profile and becoming uninsurable (see Sawers 2017). Overall, we expect a more granular assessment that allows targeting of profitable segments.

Moral hazard, i.e. the lack of incentive to guard against risk in the presence of insurance, is influenced by short-term ad hoc insurance coverage (see also, e.g. Weber 2014). Given the contiguity between the activation of cover and the coverage period, adverse behaviour may gain in importance. In addition, on-demand insurance may increase the risk of fraud, especially if insureds can turn on their insurance after a loss event. Empirical evidence supports the supposition that online-based insurance products and processes are more likely to attract fraudsters and increase moral hazard. For example, Köneke et al. (2015) discuss that cheating can be more tempting when filing an anonymous damage report on an online platform compared to face-to-face contact with an insurance agent. On the other hand, increased data exchange also increases the potential for automatic fraud detection (Gomes et al. 2021).

\section{Prevention, automation, marketing}

Short contract periods and the renewal of underwriting entail more numerous contacts between the customer and the insurer. Over the iterations, experience can be built for the pricing and personalised preventive measures can be proposed. The preventive message can be specific according to the insured items that are at risk, and data-driven coverage (including, e.g. geographic localisation and insurance activation patterns) allows insurers to further individualise prevention (The Geneva Association 2021; Pugnetti and Seitz 2021; Stöckli et al. 2019). Such prevention includes warnings or impact-reducing measures such as early loss detection and emergency services. Although microcoverage and microduration lead to micropayments, the claims process requires full customer attention to satisfy the claims. To create value for the insurer, the cost structure must be lean. In this context, Stöckli et al. (2019) note that new distributed-ledger technologies such as blockchain provide significant potential to save costs. Insurtech companies face high initial IT investments and need to be able to scale up and keep variable costs low. The scalability of technology is a key success factor (Roberts et al. 2020). Thereby, full automation, the use of artificial intelligence and a high degree of self-administration by customers will 
be key to addressing the costs and making on-demand insurance profitable. Finally, the increase in the number of client contacts can create value for the insurer in terms of reputation and branding, increasing awareness and presence of the brand, respectively. In that sense, incumbent insurers should clarify their strategy about their role. They can be risk carriers behind a new brand or use their strong market presence and propose on-demand contracts as an additional service to their own customers. On-demand insurance apps may open possibilities for cross-selling and generating additional fee income. As EIOPA (2020) notes, regarding the rise of platform business, insurance might become an ancillary offering of a wider service or product purchase.

\section{Summary of business model components}

In Table 5, we summarise the findings on the four components of the business model that discussed above. We develop a taxonomy following an inductive approach (see, e.g. Nickerson et al. 2012). Dimensionalising the business model illustrates the heterogeneity of potential models in practice and underlines the importance of optimally aligning the dimensions to create value.

The first component ('Who is addressed?') outlines which needs of selected segments on-demand insurers address (see the 'Who is the customer?' section). Examples are temporary car insurance for low-frequency drivers, travel insurance for private adventurers or liability insurance for self-employed gig economy workers. The typical segments are individuals and households, micro firms and self-employed entrepreneurs as well as small- and medium-sized enterprises. The second component summarises our findings about the value proposed to customers (see the 'What is the value proposed to the customer?' section). We record the common value propositions as observed empirically (e.g. personalised pricing, customised coverage, convenience and control) or derived on a conceptual basis (i.e. joy and gamification or servitisation). Coverage for specific single risks such as loss of life, costs related to accidents or illness, financial consequences from issues during travel, liability or legal expenses, loss from destruction or theft of movables, is the core insurance product. We also lay out how customers can access on-demand insurance. Besides the traditional distribution channels, on-demand insurance is well suited to be embedded in digital ecosystems, for example those centering around sharing, mobility or homes. The question about how the value proposition is created addresses the dimensions of the operational model, the third component that we discussed in the How is the value proposition created?' section. We group different ways of organising risk capacity as well as potential areas of value chain engagement. Our inductive study of current market offers reveals that many insurtech companies presenting themselves as on-demand insurers are in fact intermediaries with different degrees of independence from insurance carriers where the risk is placed. The choice of coverage activation and claims payment triggers, both ranging from manual to fully automatic (see Table 1), is of operational interest for on-demand insurers driving the choice of technology, costs and potential data capture. We add the type and frequency of data exchange as an important dimension because the information 
On the (Future) Role of On-Demand Insurance
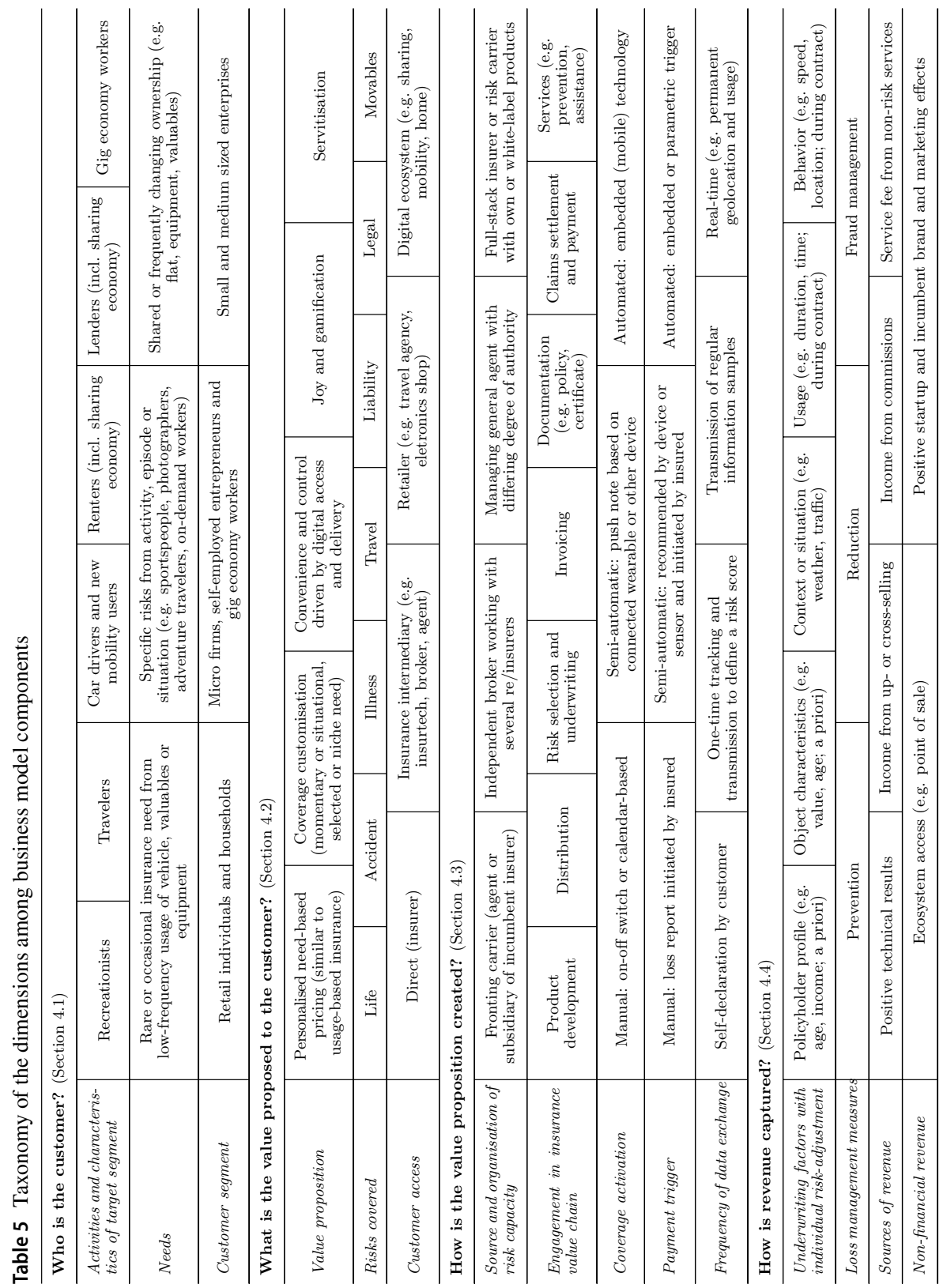
captured from customers depends on the value proposition. The fourth component summarises the dimensions of value appropriation discussed in the 'How is revenue captured?' section. We record the range of underwriting (pricing) factors and loss management measures that on-demand insurers might use. Notably, on-demand insurance opens the opportunity to price risks more granularly and continuously by using object-, context-, usage- or behaviuor-based risk factors and to engage in risk mitigation in addition to risk financing. Key to the success of on-demand insurers will be capturing one or several sources of financial and non-financial revenue.

Our analysis reveals that some components of the business model are of particular importance to the success of on-demand insurance. Adequate pricing based on dynamic and continuous underwriting will be a prerequisite considering that on-demand insurance is taken out for short contract periods at times of higher risk exposure. However, even for small premium installments the possibility to increase premiums will be limited by demand. Therefore, the success of on-demand insurance rests on the ability to collect and leverage risk data to prevent losses from happening in the first place, to automate fraud detection and to tap into further sources of revenue beyond technical results. A fully digital, scalable and interoperable infrastructure with seamless, smart loss handling processes is the backbone of competitive advantage.

\section{Customer perspectives from a survey in Switzerland}

Although on-demand offerings are emerging and the topic is being discussed in the practice-oriented literature as well as in some academic contributions, there is not yet a study covering the customer's viewpoint so far. We therefore conducted a survey with a particular focus on leisure equipment and mobile devices to discover how widespread the knowledge of and interest in on-demand insurance is among the general population in Switzerland.

\section{Survey setup and panel of respondents}

The survey was conducted online by a professional polling agency in the Germanspeaking part of Switzerland in spring 2020. Focusing on the German-speaking community is common for Switzerland and covers around two thirds of the population. Although few on-demand insurance solutions are available in Switzerland, the country is an interesting case due to its high insurance penetration and insurance density. Participants for the survey were recruited by the agency from a representative panel.

While 1,206 people took part in the survey, we analysed 1,117 responses after excluding non-respondents (non-response error; Döring and Bortz 2016, p. 216). The final sample includes slightly more male $(51 \%)$ than female $(49 \%)$ respondents. The age groups are defined as follows and rather equally represented: 18-30 years (22\%), 31-45 years $(24 \%), 46-60$ years $(26 \%)$, and $60+$ years $(27 \%)$. The respondents are all in charge of deciding on insurance matters in their household and have 
at least one insurance policy. The vast majority (95\%) of the respondents own liability insurance. Further, the majority have supplementary health insurance (80\%), motor vehicle insurance $(79 \%)$, legal expenses insurance $(58 \%)$ or travel insurance (53\%). Owners of insurance products such as life insurance $(30 \%)$ or mobile phone/ tablet insurance $(18 \%)$ have a lower prevalence. From the observation that more than half of the surveyed persons own legal expenses and travel insurance, we conclude that the respondents have a high insurance literacy and interest in buying insurance cover. This must be kept in mind when interpreting the results. In the following, we discuss selected survey questions and lay out some descriptive statistics. The wording of these survey questions, translated from the original German version, is provided in the Appendix.

\section{Awareness of limitations in traditional household insurance cover}

In our survey, we focused on insurance for recreational equipment (e.g. bikes or ski or photo equipment) and mobile devices (e.g. smartphones, tablets) that people tend to take with them when leaving the house. A large majority of the respondents $(81 \%$, cf. Question 1) know that items stolen outside the place of residence (by simple theft, i.e. events which cannot be qualified as burglary or robbery) are not covered by their standard household insurance but can be insured through an additional coverage. Only $46 \%$ of the persons questioned have a separate endorsement to include the risk of simple theft (Question 2).

\section{Perceived risk and interest in using on-demand insurance}

To assess the risk profile, we asked how bad the loss or damage of a selection of items would be (see Question 4). Thereby, we consider only persons who possess one of the items (Question 3). More than half of the respondents (see the results in Table 6) perceive the loss or damage of expensive jewellery or watches (86\%), smartphone or tablet (71\%), and photographic equipment $(67 \%)$ as bad or very bad. In contrast, the loss or damage of golf equipment is considered as bad or very bad by only $39 \%$ of the respondents. Apart from expensive jewellery or watches, one can conclude that the more common-place an item is, the worse its loss or damage is (see smartphones or tablets, bikes, and photographic equipment). As the value of the items was not asked, we do not know whether the perceived loss is a monetary, emotional or administrative burden. Indeed, in the case of photographic equipment for example, the loss of pictures might be more severe than the financial loss of the camera. This makes it difficult to compare with, e.g. golf equipment.

Only a small proportion of the above owners would insure their belongings occasionally with on-demand insurance (Question 5). For the survey participants, insurance for expensive jewellery or watches (44\%), diving equipment (42\%) and drones (35\%) are among the most popular coverage when looking at the response options 'very likely' and 'most likely'. We observe that, while the interest in on-demand insurance for jewellery is in line with the badness of the loss or damage of the item (see above and Table 6), this does not hold for the large population of owners of 
Table 6 Perception of loss or damage and usage of on-demand insurance for selected items

\begin{tabular}{llll}
\hline Item & $\begin{array}{l}\text { Number (share, \%) } \\
\text { of owners }\end{array}$ & $\begin{array}{l}\text { Perception of loss or } \\
\text { damage }(\%)\end{array}$ & $\begin{array}{l}\text { Interest in on- } \\
\text { demand insurance } \\
(\%)\end{array}$ \\
\hline Expensive jewellery or watches & $279(25)$ & 86 & 44 \\
Smartphone or tablet & $1090(98)$ & 71 & 28 \\
Mountain bike, e-bike, or racing bike & $332(30)$ & 69 & 31 \\
Photographic equipment & $374(33)$ & 67 & 35 \\
Drone & $55(5)$ & 53 & 38 \\
Diving equipment & $33(3)$ & 52 & 42 \\
Ski or snowboard equipment & $325(29)$ & 51 & 29 \\
Golf equipment & $33(3)$ & 39 & 33
\end{tabular}

The share of owners refers to the total number of respondents $(N=1,117)$. In the columns 'perception of loss or damage' (answers 'bad' and 'very bad') and 'interest in on-demand insurance' (answers 'quite likely' and 'very likely'), the shares relate to the number of owners for each item. The items are ordered by decreasing perception of loss or damage

smartphones and tablets (98\%): their interest is lowest while their perception of loss is second highest. Overall, the interpretation of a link between the perceived risk and the interest in insurance is delicate. Finally, we note that special caution must be exercised when considering the results for drone, diving equipment and golf equipment owners since these represent less than $5 \%$ of the sample.

\section{Value for customers: advantages and disadvantages}

The respondents see the flexibility of on-demand insurance as its biggest advantage (76\% strongly or rather agree in Question 6), followed by the possibility to adequately cover particularly important items (73\%). A majority also sees it as a new, modern solution $(55 \%)$ that can cover risks that have not yet been reasonably insured (60\%). Furthermore, it is considered fair by $54 \%$ as it follows the 'pay-as-you-use' principle. In contrast, it is not seen as particularly transparent $(28 \%)$ or cheaper (23\%) compared to standard insurance policies on a yearly-contract basis. This result may seem surprising, since it is precisely transparency that is mentioned in theory as an advantage of digital insurance solutions (Bühler and Maas 2016; Braun and Schreiber 2017). However, recalling that the respondents have a high insurance literacy, it is less striking that few people find on-demand insurance more transparent or cheaper than traditional insurance.

In answer to Question 7, most respondents consider the risk of double insurance $(65 \%)$ and forgetting to deactivate the insurance coverage after usage (58\%) as major drawbacks (considering the answers 'strongly agree' and 'rather agree'). Further, $41 \%$ of the respondents fear that the model attracts insurance fraud. Further disadvantages of the product are that it is considered superfluous $(27 \%)$, too cumbersome $(23 \%)$, and too complex or difficult to understand $(17 \%)$. The last result may 
be rooted in the high financial literary of the respondents and may thus not hold for a different population. We report all survey results in Table 7.

\section{Awareness and potential use of on-demand insurance}

On the one hand, we observe that $10 \%$ have already heard of on-demand insurance and 2\% have already seen offers (cf. Question 8). On the other hand, we find that, overall, 23\% of the respondents are 'very likely' or 'rather likely' to imagine, in principle, using on-demand insurance (cf. Question 9). In terms of occasions, more than half of the respondents can imagine ('very likely' and 'quite likely' in Question 10) using insurance on a daily basis for selected trips $(62 \%)$ or holidays in general $(52 \%)$. For renting or lending objects, respectively, about $37 \%$ and $29 \%$ would still consider on-demand insurance. About two thirds (66\%) of the respondents consider well-known insurance companies as the most likely providers or sales channels sought by potential customers (Question 11). One quarter $(25 \%)$ would consider online insurance companies while $21 \%$ and $18 \%$ would take out insurance with the manufacturer or the seller of the item to be insured, respectively (see the discussion on the point of sale in the section 'Who is the customer?'). Only $17 \%$ would consider online price comparison platforms. Inventory app providers and technology companies, like Google and Amazon, each only attract $5 \%$ of the votes.

\section{Profiles of potential customers}

The findings from our survey confirm several results from e.g. KPMG (2017) and Tata Consultancy Services (2019). Notably, we observe that the respondents from the lower age classes show a stronger interest compared to the older respondents; for example, respondents aged between 18 and 30 years report an average interest of 3.07 while those aged 60+ years have an average interest of 2.71 (see Table 8). Further, we find a positive correlation between digital literacy and the intention to use on-demand insurance. For example, among those that are very likely to use on-demand insurance, we find, on average, a practice of doing things online that is about one level higher (4.8 versus 3.9 ) when compared to those that do not at all imagine using on-demand insurance. In terms of risk-taking behaviour, we find that those intending to take out on-demand insurance are more likely to pursue risky leisure activities. Similarly, the most interested respondents are those that regularly travel to distant countries and undertake regular weekend trips. Regarding the various insurance-buying behaviours that we consider, we find that the most interested respondents are used to doing as much as possible online, are ready to change their insurer for a cheaper offer, and mostly search for information and try to understand themselves. 
Table 7 Potential advantages and disadvantages as perceived by the survey respondents

Advantages and disadvantages

\begin{tabular}{lr} 
Potential advantages: On-demand insurance & 76 \\
...enables flexible protection in terms of timing and duration & 73 \\
...allows to adequately insure the items that are important to me & 60 \\
...enables protection against risks for which no sensible solution exists yet & 55 \\
...is more modern than traditional insurance & 54 \\
...is fairer because everyone pays for what they need & 28 \\
...is more transparent than traditional insurance & 23 \\
...is cheaper than traditional insurance & \\
Potential disadvantages: On demand-insurance & 65 \\
....contains the risk of double insurance & 58 \\
...is tricky: it's easy to forget to deactivate & 41 \\
...attracts people who want to abuse insurance (insurance fraud) & 34 \\
...is more expensive than traditional insurance & 31 \\
...is unnecessary over-insurance & 27 \\
...is superfluous & 23 \\
...is too cumbersome & 17 \\
...is too complex or too difficult to understand & 37 \\
\hline
\end{tabular}

The level of agreement reports the percentage of the answers 'strongly agree' and 'rather agree'

\section{Functions raising potential customers' enthusiasm}

Using the Kano model (Kano et al. 1984), we measure the respondents' opinions on various attributes of an on-demand website or app in an implicit way. In Question 17 , for several product features, the participants answer two questions, one of which is formulated in a positive way (functional) and the second one in a negative way (dysfunctional). From the responses ('I like it', 'I expect it', 'I am neutral', 'I can tolerate it', 'I dislike it') we derive the type of quality of each attribute along the standard classification displayed in Table 9 (adapted from Ma et al. 2019, Table 3).

In Table 10, we report the results along the qualities of the Kano model. The left panel provides the qualification from the whole sample of respondents, while the right panel considers the subsample of respondents that identify themselves as 'quite likely' or 'very likely' users (cf. Question 18). When analysing the frequency of the answers received from the whole sample of respondents (left panel of Table 10), we observe that between $34 \%$ and $57 \%$ are indifferent about the presented product attributes. Nevertheless, in most cases, we notice that the second strongest dimension is enthusiasm, with $20 \%$ to $32 \%$ of the responses. The only feature that shows a comparatively strong rejection (32\%) is the function of automatically switching insurance on and off. We did not ask respondents to justify their choice, but it can be assumed that there prevails a certain scepticism towards fully automated insurance 
Table 8 Characterisation of potential on-demand customer profiles

\begin{tabular}{|c|c|c|c|c|c|c|}
\hline \multirow[t]{3}{*}{ Overall shares } & \multicolumn{6}{|c|}{ "In principle, I could imagine using on-demand insurance" } \\
\hline & Very likely & Quite likely & Maybe & Probably not & Not at all & Average \\
\hline & $6 \%$ & $18 \%$ & $47 \%$ & $23 \%$ & $6 \%$ & 2.95 \\
\hline \multicolumn{7}{|l|}{ Demographic criteria } \\
\hline Gender (male) & $55 \%$ & $54 \%$ & $51 \%$ & $50 \%$ & $54 \%$ & 2.96 \\
\hline Gender (female) & $45 \%$ & $46 \%$ & $49 \%$ & $50 \%$ & $46 \%$ & 2.93 \\
\hline Age $18-30$ years & $26 \%$ & $27 \%$ & $22 \%$ & $21 \%$ & $12 \%$ & 3.07 \\
\hline Age $31-45$ years & $26 \%$ & $27 \%$ & $27 \%$ & $20 \%$ & $16 \%$ & 3.05 \\
\hline Age $46-60$ years & $30 \%$ & $27 \%$ & $26 \%$ & $24 \%$ & $26 \%$ & 2.98 \\
\hline Age $60+$ years & $18 \%$ & $19 \%$ & $25 \%$ & $35 \%$ & $46 \%$ & 2.71 \\
\hline \multicolumn{7}{|c|}{ Digital literacy (Questions 12 and 13) } \\
\hline $\begin{array}{l}\text { Skills with electronic } \\
\text { devices }\end{array}$ & 4.4 & 4.1 & 4.0 & 3.9 & 3.8 & \\
\hline $\begin{array}{l}\text { Practice doing things } \\
\text { online }\end{array}$ & 4.8 & 4.4 & 4.2 & 4.1 & 3.9 & \\
\hline \multicolumn{7}{|l|}{ Risk-taking behaviour (Question 14) } \\
\hline (a) In the area of finance & 2.9 & 2.7 & 2.5 & 2.3 & 2.2 & \\
\hline (b) In leisure activities & 3.3 & 3.2 & 2.9 & 2.7 & 2.4 & \\
\hline \multicolumn{7}{|l|}{ Travel behaviour (Question 15) } \\
\hline (a) Regular distant travel & 3.6 & 3.5 & 3.1 & 2.8 & 3.0 & \\
\hline (b) Regular weekend trips & 3.5 & 3.3 & 3.0 & 2.8 & 2.7 & \\
\hline \multicolumn{7}{|c|}{ Insurance-buying behaviour (Question 16) } \\
\hline As much as possible online & 4.0 & 3.5 & 3.3 & 3.2 & 2.8 & \\
\hline Looking for an advisor & 3.3 & 3.6 & 3.6 & 3.3 & 3.0 & \\
\hline Change for a cheaper offer & 3.0 & 2.8 & 2.8 & 2.5 & 2.2 & \\
\hline Search and understand & 4.3 & 4.1 & 3.9 & 3.8 & 3.6 & \\
\hline
\end{tabular}

The underlying subsample in this table accounts for 1,093 respondents with a level of agreement between 'not at all' and 'very likely' in the answer to Question 9. For the average levels presented in the column 'average', the answers to Question 9 have been transformed from the five-level Likert scale into numbers from 1 ('not at all') to 5 ('very likely'). For the average levels presented in the 'digital literacy', 'risktaking behaviour' and 'insurance-buying behaviour' sections, the answers to Questions 12 through 16 have been transformed from the five-level Likert scales into numbers from 1 ('strongly disagree') to 5 ('strongly agree')

solutions in connection with, for example, location approval. This element certainly deserves further analysis.

If we limit our analysis to the responses of the subsample of 335 (30\%) likely users (right panel of Table 10), we get a more differentiated picture. Indeed, potential users are more enthusiastic about the presented product features and most frequently rate the attributes as attractive (frequencies between $28 \%$ and $44 \%$ ). Still, $39 \%$ are indifferent about the feature of displaying borrowed items, while $36 \%$ would find it attractive. A reminder for the expiry of guarantees (24\%), programming insurance through a calendar (23\%), and receiving tips in the event of a claim 
Table 9 Qualities of product attributes along the functional and dysfunctional perception

\begin{tabular}{llllll}
\hline & \multicolumn{2}{l}{ Dysfunctional } & & \\
\cline { 2 - 5 } & I like it & I expect it & I am neutral & I can tolerate it & I dislike it \\
\hline Functional & & & & \\
I like it & Questionable & Attractive & Attractive & Attractive & One-dimensional \\
I expect it & Reverse & Indifferent & Indifferent & Indifferent & Must-be \\
I am neutral & Reverse & Indifferent & Indifferent & Indifferent & Must-be \\
I can tolerate it & Reverse & Indifferent & Indifferent & Indifferent & Must-be \\
I dislike it & Reverse & Reverse & Reverse & Reverse & Questionable \\
\hline
\end{tabular}

Product features presented in Question 17 are assessed by asking participants two questions: 'How would you feel if this product feature existed?' and 'How would you feel if this product feature would not exist?' Thereby, one question is formulated in a positive way (functional) and one question is formulated in a negative way (dysfunctional). In each dimension the response is chosen among five answer options. The type of quality of the product attributes are derived from the table

(24\%) are viewed as performance features ('one-dimensional') and have the secondhighest number of responses. As in the overall sample, we see an important share of respondents being critical towards automatic activation and deactivation of insurance $(26 \%)$.

\section{Discussion on the future role of on-demand insurance}

Wrapping up our market study ('Landscape and characteristics of offers' section), business model analysis ('Dimensions of the business model' section) and insights on customer perceptions ('Customer perspectives from a survey in Switzerland' section), the question arises whether on-demand insurance creates enough value for both customers and providers to develop from a niche phenomenon to a new way of covering risks. Our findings indicate that on-demand insurance offerings address certain customer needs better than traditional insurance offerings. In particular, ondemand insurance picks up the trend of instantly responding to a specific need and using digital technology to do so. In this way, buying insurance feels more modern and gives customers more control over selected personal insurance needs. However, our customer survey also suggests that individuals do not view on-demand insurance as particularly more transparent or cheaper when compared to standard insurance policies on a yearly contract basis. From the perspective of insurance economics, we find that underwriting profit is limited. Still, we observe that incumbents cooperate with on-demand technology providers and on-demand insurers. We therefore assume that incumbents see potential in the on-demand insurance business model beyond niche segments, an assumption which we further explore in the 'Insurance economics and potential' section. However, the insurance industry does not easily transform, as we outline in the 'Scope of business model innovation' section by studying the scope of business model innovation. 


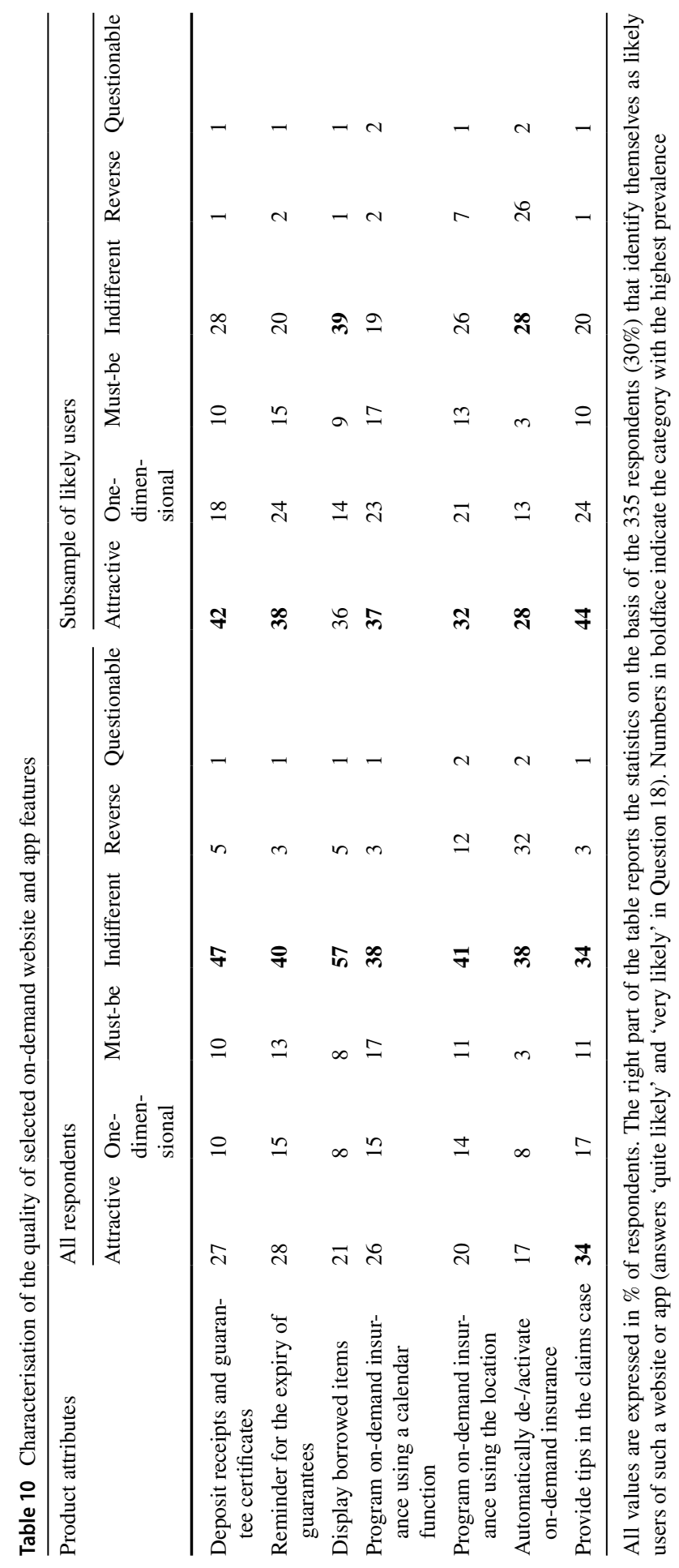




\section{Insurance economics and potential}

Against the background of insurance economics, we conclude that the profit margin is limited given the value proposition and that a high degree of automation and a large volume of customers will be key to economic success. Hence, underwriting profit is not the decisive driver of change for the insurance industry. However, a purely technical view falls short of considering the advantages that mastering ondemand insurance brings for insurance companies: providing insurance solutions at the point of need, unbundling cover and services into individualised offers, capturing risk-relevant data as per instant and digital delivery of the product, and co-creating solutions with partners in a digital ecosystem. Interestingly, early on-demand movers did not develop into full-stack insurance companies but grew into insurance technology providers. For these firms, their on-demand offerings served as a testing ground.

While much attention is given in research and practice to the emergence of insurtech companies, we also observe some evolution among incumbents. Ondemand options are increasingly offered within traditional products (e.g. Ikea/ iptiQ Hemsäker), as an integral aspect of newly developed products (e.g. AXA XL cyber) or marketed as a new type of offer addressing customer demand for more flexible coverage (e.g. AIG Travel App, Allianz Hobbisure, Zurich Klinc). Hence, we observe that incumbent insurance companies not only experiment with the concept of on-demand insurance with peripheral niche products but adopt it to improve existing insurance products with on-demand features. Against that background, mastering the demand business model is the gateway to modularising and personalising insurance offers, to address an increasingly segmented market of customers who expect intelligent and flexible products. However, such transformation is challenging given the legacy systems and structures of incumbent insurers (Bauer et al. 2021).

\section{Scope of business model innovation}

The shift from annually renewing standardised policies with a priori pricing to flexible coverage periods is novel and non-trivial to the insurance industry. The capability to offer on-demand insurance requires business model innovation by incumbents. To outline the potential scope of business model transformation among insurers, we adapt the framework of Foss and Saebi (2017) to on-demand insurance.

Foss and Saebi (2017) differentiate between modular and architectural innovation in terms of scope and novelty along the dimensions of newness to the firm versus the industry. Indeed, a majority of insurers has already undergone evolutionary business model innovation in the context of digitisation. Digital appearance and marketing, multi-channel access, or direct online insurance are examples of this transformational step. The capability to do business in a digital and customer-centric manner is certainly a prerequisite of engaging in on-demand insurance. The success of insurtech companies and expectations that customers bring from e-commerce experiences forces insurers to adapt the architecture of their business model. Online business is not just a customer-facing value proposition but is integrated across the 
business model components. Insurers struggle with such architectural innovation due to their long history of a highly product-orientated organisational structure, high vertical integration, and infrastructure legacy. For this reason, insurers also actively engage in disrupting their business model. Business model innovation is called focused "when a firm innovates in one area, such as targeting a new market segment that has been ignored by its competition" (Foss and Saebi 2017, p. 217). The phenomenon that incumbents cooperate with insurtech companies and experiment in niches such as situational travel or equipment insurance are examples of focused business model innovation in the context of on-demand insurance. Indicative of this type of business model innovation is that innovation happens in labs. This type of innovation typically requires a modular change to the prevailing business model. Complex business model innovation, however, affects the business model in its entirety. Insurtech companies particularly strive to change the architecture of all components of the business model. These new entrants align the entirety of their system to an on-demand value proposition delivering an individualised and fully digital experience from purchase, payment, documentation, claims trigger, reimbursement and termination. We summarise the typology in Table 11.

Several factors moderate the scope of business model innovation in the insurance industry. First of all, there are the typical boundary conditions and antecedents of business model innovation such as financial pressure, stakeholder expectations, new competition, and low technological progress. We have discussed them in the business model analysis in the 'Dimensions of the business model' section. Besides boundary conditions, several macro- and micro-level factors moderate an insurer's transition to an on-demand model.

\section{Macro-level factors}

Several macro-level factors slow down the pace of innovation. The potential to automate on-demand insurance depends on the willingness of insureds to share data (Miesler and Bearth 2016; Pugnetti and Elmer 2020; see also the 'Customer perspectives from a survey in Switzerland' section). Additionally, ethical (e.g. use of genetic information), social (e.g. exclusion of risks with certain risk factors) and legal aspects (e.g. protection of sensitive data) limit the use of risk-related data. As data might have to be shared with partners to provide on-demand insurance at the point of need, transparency regarding the use, privacy, and security of the data is key (Wiegard and Breitner 2019). Moreover, a low level of transaction and online engagement (Gebert-Persson et al. 2019) and low awareness (Hohl et al. 2020) limit the scope for business model innovation. Finally, large-scale distribution of ondemand insurance could lead to issues of exclusion and market failure as 'bad' risks no longer find acceptable offers. As a consequence, regulators might step in, especially in areas where insurance cover is socially wanted (Lewis 2017; Vereinigung der Bayerischen Wirtschaft 2017; McFall and Moor 2018). 
Table 11 Typology of business model innovation (adapted from Foss and Saebi 2017, Fig. 3)

\begin{tabular}{|c|c|c|}
\hline & \multicolumn{2}{|l|}{ Scope } \\
\hline & Modular & Architectural \\
\hline \multicolumn{3}{|l|}{ Novelty } \\
\hline New to firm & $\begin{array}{l}\text { Evolutionary Driven by technological } \\
\text { progress and changing customer needs, } \\
\text { insurers digitise components of the } \\
\text { business model (e.g. digital marketing, } \\
\text { multi-channel). }\end{array}$ & $\begin{array}{l}\text { Adaptive Driven by competitive } \\
\text { pressure from new entrants and } \\
\text { innovative competitors, insurers } \\
\text { change the business model and } \\
\text { align all components to the new } \\
\text { digital and customer-centric } \\
\text { value proposition. }\end{array}$ \\
\hline New to industry & $\begin{array}{l}\text { Focused Incumbents cooperate with } \\
\text { insurtech companies and experiment } \\
\text { with selected on-demand products. }\end{array}$ & $\begin{array}{l}\text { Complex Insurance is offered } \\
\text { instantly and digitally delivered } \\
\text { at the point of need (via ecosys- } \\
\text { tems, platforms, suppliers). }\end{array}$ \\
\hline
\end{tabular}

'New to firm' relates to innovations where changes to the business model are typically driven by external pressure. 'New to industry' relates to innovations where the management actively engages in disruption

\section{Micro-level factors}

Incumbent insurers typically host decade-old legacy systems that make it difficult to start digitisation projects from scratch (Eling and Lehmann 2018; Pousttchi and Gleiss 2019). Therefore, it is not surprising that on-demand insurance is developed by insurtech startups partnering with incumbents for risk capacity and brand name. Roberts et al. (2020) observe that full-stack insurers are relatively new companies, growing quickly but at year-end 2019, operating at a loss. They further find traditional insurers and reinsurers to be among the main acquirers of insurtech companies. Further firm-level factors that explain the prominence of startups are differences in the organisations' culture, especially regarding shared values, tolerance of failure, risk aversion, innovation, tech affinity, and savviness (Mazzini 2021). Roberts et al. (2020) also note that insurers face considerable risks in projects that involve underwriting processes in contrast to claims-related innovation projects, as errors may have a large financial impact.

\section{Other factors}

Foss and Saebi (2017) identify firm-level factors that influence business model innovation such as managerial cognition towards loss-aversion, openness to change, leadership characteristics, or culture. As our research focuses on the on-demand business model and not the individual firm, we do not discuss these any further.

In sum, the above-mentioned range of moderators helps to understand why the insurance industry engages in adaptive and focused innovation in contrast to complex business model innovation. More empirical research is now needed to substantiate the influence of the various factors related to the emergence of on-demand insurance as a sustainable business model. 


\section{Conclusion}

Given the lack of research on the emergent topic of on-demand insurance, our ambition is to advance the understanding of this phenomenon and the impact it might have on the insurance industry. For that purpose, we define on-demand insurance to differentiate it from related terms and outline common characteristics of current market offers. We furthermore study the dimensions of the business model to better understand value creation and provide a customer perspective based on survey data. On this basis, we discuss the future role of on-demand insurance and why the pace of innovation among incumbent insurers is lagging. The results of this paper contribute to the literature studying the rapid development in the insurance industry that is driven by exploiting technology to provide innovative insurance solutions for changing customer needs. By providing comprehensive knowledge about the meaning, mechanism, and value of insurance on-demand, we lay the foundation to discuss its future role and implications for traditional insurers.

The observation that many current providers are intermediaries and not full-stack insurers leads us to suggest that value creation currently is mainly about organising access to coverage in novel ways rather than capturing profit from technical underwriting. The results from the customer survey in Switzerland as well as business model analysis suggest that novelty in respect to instant and flexible insurance is the key value driver from the customers' perspective. The evidence from our customer survey concerning increasing efficiency is mixed. It is yet unclear whether the results are indicative of on-demand insurance remaining a niche phenomenon or whether they are an expression of a transformational phase.

From the perspective of incumbent insurers, we identify complementarity as a central value driver to engage in on-demand insurance. We argue that mastering on-demand insurance goes hand in hand with being able to take a broader role in digital ecosystems. Against the background of changing work, life and ownership styles, we expect the demand for more flexible and instant insurance coverage to grow. Our market research shows that, as of today, it is mainly insurtech companies joining forces with incumbent insurers that operate in the background to address this rising need. Insurers are facing challenging macro- and micro-factors that moderate their pace of business model innovation. Even though technology providers and insurtech companies can fill some of the gaps, traditional insurers cannot avoid business model innovation if they want to play a significant and sustainable role at the customer interface in the future. Insurers are therefore advised to look beyond technical results and efficiency when evaluating an engagement in on-demand insurance. Our findings suggest that on-demand insurance creates value. While today's value comes from novelty and complementarity, extensive value can be unlocked regarding efficiency and lock-in of customers with maturing technology and well-aligned business model components.

Our results have to be interpreted against some limitations. The results are not exhaustive given the qualitative and interpretative nature of our research on this new and fast-changing phenomenon. Even though our results are based on empirical evidence and theoretical considerations, the choice of offerings analysed could suffer 
from sample bias. More empirical work is needed to substantiate the results. In particular, with value increasingly being created in partnerships and ecosystems, more focus should be given to study network structures and value created through coopetition on multi-sided digital platforms. There also remain many research questions concerning the concept itself. For example, open questions regarding the impact of on-demand solutions on the concept of solidarity and the economics of pooling. Indeed, insurers may find it difficult to pool the risks if the risks that are covered can change continuously and risk pools become smaller. Further, the instant availability of data allows for new types of analyses. The latter may allow the development of additional services, e.g. for prevention, and may lead to a shift in perspectives from risk financing to prevention.

\section{Appendix: Summary of survey questions}

Question 1 Are you aware that items which are stolen outside your place of residence are not covered by the standard household insurance but can be insured through an additional coverage? Answer options: Yes; no.

Question 2 Have you taken out such an additional coverage to include the risk of theft outside your place of residence. Answer options: Yes; no; don't know.

Question 3 Do you own one or more of the following items that you occasionally have with you on the go? (a) Smartphone or tablet; (b) Photographic equipment; (c) Mountain bike, e-bike, or racing bike; (d) Drone; (e) Diving equipment; (f) Golf equipment; (g) Ski or snowboard equipment; (h) Expensive jewellery or watches. Answer options for each item: Yes; no.

Question 4 How bad would it be for you to lose or damage one of the following items? (a) Smartphone or tablet; (b) Photographic equipment; (c) Mountain bike, e-bike, or racing bike; (d) Drone; (e) Diving equipment; (f) Golf equipment; (g) Ski or snowboard equipment; (h) Expensive jewellery or watches. Answer options for each item: Very bad; bad; neutral; not bad; not bad at all.

Question 5 For which of these items would you use on-demand insurance from time to time? (a) Smartphone or tablet; (b) Photographic equipment; (c) Mountain bike, e-bike, or racing bike; (d) Drone; (e) Diving equipment; (f) Golf equipment; (g) Ski or snowboard equipment; (h) Expensive jewellery or watches. Answer options for each item: Very likely; quite likely; maybe; probably not; not at all; I don't know.

Question 6 How do you personally assess the possible advantages of on-demand insurance? (a) Allows to adequately insure the items that are important to me; (b) Enables flexible protection in terms of timing and duration; (c) Is cheaper than traditional insurance; (d) Is more transparent than traditional insurance; (e) Enables protection against risks for which no sensible solution exists yet; (f) Is more modern 
than traditional insurance; (g) Is fairer because everyone pays for what they need. Answer options for each item: Strongly agree; rather agree; neither agree nor disagree / I don't know; rather disagree; Strongly disagree.

Question 7 How do you personally assess the possible disadvantages of on-demand insurance? (a) Contains the risk of double insurance; (b) Is unnecessary overinsurance; (c) Attracts people who want to abuse insurance (insurance fraud); (d) Is more expensive than traditional insurance; (e) Is too complex or too difficult to understand. (g) Is superfluous; (h) Is too cumbersome; (i) Is tricky: it's easy to forget to deactivate. Answer options for each item: Strongly agree; rather agree; neither agree nor disagree / I don't know; rather disagree; strongly disagree.

Question 8 Have you already heard of on-demand insurance? Answer options: Yes, I have seen offers; Yes, I heard about; I don't know; No, I don't think so; No, definitely not.

Question 9 Do you agree with the statement "In principle, I could imagine using on-demand insurance"? Answer options: Very likely; quite likely; maybe; probably not; not at all; I don't know.

Question 10 On what occasions would you use on-demand insurance most likely? (a) For holidays in general; (b) For selected trips; (c) For regular training; (d) For specific sporting events or competitions; (e) When I borrow my items; (f) When I rent or lend items from someone. Answer options for each item: Very likely; quite likely; maybe; probably not; not at all; I don't know.

Question 11 With which provider would you most likely take out on-demand insurance? (a) With a well-known insurance company; (b) With an online insurance company; (c) With the manufacturer of my beloved items; (d) With the seller of my beloved items; (e) With a comparison platform (e.g. Comparis); (f) With an Inventory app provider (e.g. Sortly); (g) With a technology company (e.g. Google, Amazon); (h) With others. Answer options: Very likely; quite likely; maybe; probably not; not at all; I don't know.

Question 12 Do you agree with the statement "I consider myself very competent in handling electronic devices (e.g. smartphone, tablet, computer)"? Answer options: Strongly agree; rather agree; neither agree nor disagree / I don't know; rather disagree; strongly disagree.

Question 13 Do you agree with the statement "I do a lot of things online (e.g. e-banking, booking trips, shopping)"? Answer options: Strongly agree; rather agree; neither agree nor disagree / I don't know; rather disagree; strongly disagree.

Question 14 Do you agree with the statement "I consider myself a risk-taking person", (a) in the area of finance? (b) in the area of leisure activities? Answer options 
for each item: Strongly agree; rather agree; neither agree nor disagree / I don't know; rather disagree; strongly disagree.

Question 15 Do you agree with the following statements? (a) "I regularly travel to distant countries." (b) "I often go on weekend trips (e.g. city trips, ski trips)." Answer options for each item: Strongly agree; rather agree; neither agree nor disagree / I don't know; rather disagree; strongly disagree.

Question 16 Do you agree with the following statements when buying insurance? (a) "I want to do as much as possible online because it is easier and faster." (b) "I am looking for someone who can give me competent advice, because then I feel more confident in making a decision." (c) "I change my insurance provider when I find a cheaper offer because I don't want to pay too much." (d) "I get detailed information about it because I want to understand everything myself as much as possible." Answer options for each item: Strongly agree; rather agree; neither agree nor disagree / I don't know; rather disagree; strongly disagree.

Question 17 Imagine that a website or app offers you the option of entering personal items in a digital inventory and insuring them on demand. In the following, we show various features of such an app or website. Please evaluate the presence and the lack of each of the features. (a) Deposit receipts and guarantee certificates; (b) Reminder for the expiry of guarantees; (c) Display borrowed items; (d) Program on-demand insurance for individual items using a calendar function (e.g. for certain trips); (e) Program on-demand insurance using the location (e.g. when leaving home or the country); (f) Automatically de-/activate on-demand insurance for selected items in specific situations; (g) Provide tips in the claims case (e.g. police report, repair, data backup).

- How would you feel if this product feature existed? Answer options for each item: I like it; I expect it; I am neutral; I can tolerate it; I dislike it.

- How would you feel if this product feature would not exist? Answer options for each item: I like it; I expect it; I am neutral; I can tolerate it; I dislike it.

Question 18 How likely would you be to use such an app or website? Answer options: Very likely; quite likely; maybe; probably not; not at all; I don't know.

Funding Open access funding provided by University of Lausanne.

Open Access This article is licensed under a Creative Commons Attribution 4.0 International License, which permits use, sharing, adaptation, distribution and reproduction in any medium or format, as long as you give appropriate credit to the original author(s) and the source, provide a link to the Creative Commons licence, and indicate if changes were made. The images or other third party material in this article are included in the article's Creative Commons licence, unless indicated otherwise in a credit line to the material. If material is not included in the article's Creative Commons licence and your intended use is 
not permitted by statutory regulation or exceeds the permitted use, you will need to obtain permission directly from the copyright holder. To view a copy of this licence, visit http://creativecommons.org/licen ses/by/4.0/.

\section{References}

Amit, R., and C. Zott. 2001. Value creation in E-business. Strategic Management Journal 22 (6-7): 493-520.

Barry, L., and A. Charpentier. 2020. Personalization as a promise: Can big data change the practice of insurance? Big Data \& Society 7 (1): 1-12.

Bauer, D., J. Tyler Leverty, J. Schmit, and J. Sydnor. 2021. Symposium on insure-tech, digitalization, and big-data techniques in risk management and insurance. Journal of Risk and Insurance 88 (3): 525-528.

Braun, A., and M. Haas. 2019. On-demand insurance: A relevant alternative to standard products? In Innovation in the European Insurance Industry, ed. A. Eckstein, A. Funk-Münchmeyer, and A. Liebetrau, 75-80. Karlsruhe: Verlag Versicherungswirtschaft.

Braun, A., M. Haas, C. Hildebrand, and P.D. Thistle. 2020. Adverse selection in insurance markets: ondemand contracts as a screening device. SSRN Electronic Journal. https://doi.org/10.2139/ssrn. 3694973

Braun, A. and F. Schreiber. 2017. The current InsurTech landscape: Business models and disruptive potential. St. Gallen: Institute of Insurance Economics I.VW-HSG, University of St. Gallen.

Bühler, P., and P. Maas. 2016. Kunden transformieren die Versicherungsmärkte. In Digitale Transformation im Unternehmen gestalten, ed. O. Gassmann and P. Sutter, 99-113. München: Carl Hanser.

Churchill, C. 2006. Protecting the poor: A microinsurance compendium. Geneva: International Labour Office.

Döring, N., and J. Bortz. 2016. Forschungsmethoden und Evaluation in den Sozial- und Humanwissenschaften. Springer, Berlin: Springer-Lehrbuch.

Eling, M., and M. Lehmann. 2018. The impact of digitalization on the insurance value chain and the insurability of risks. The Geneva Papers on Risk and Insurance-Issues and Practice 43 (3): 359-396.

Eling, M., S. Pradhan, and J.T. Schmit. 2014. the determinants of microinsurance demand. The Geneva Papers on Risk and Insurance-Issues and Practice 39 (2): 224-263.

EIOPA. 2018. Seventh consumer trends report. European Insurance and Occupational Pension Authority.

EIOPA. 2020. Discussion paper on the (re)insurance value chain and new business models arising from digitalisation.

Fitzgerald, M., N. Kruschwitz, D. Bonnet, and M. Welch. 2013. Embracing digital technology: A new strategic imperative. Cambridge: Massachusetts Institute of Technology.

The Geneva Association. 2021. From Risk Transfer to Risk Prevention: How the Internet of Things is reshaping business models in insurance. Authors: Isabelle Flückiger and Matteo Carbone. May.

Foss, N.J., and T. Saebi. 2017. Fifteen years of research on business model innovation. Journal of Management 43 (1): 200-227.

Gassmann, O., K. Frankenberger, M. Choudury, and M. Csik. 2020. The business model navigator. Limited: Pearson Education.

Gassmann, O., K. Frankenberger, and M. Csik. 2017. Geschäftsmodelle entwickeln - 55 innovative Konzepte mit dem St. Galler Business Model Navigator. München: Carl Hanser Verlag.

Gassmann, O., and P. Sutter. 2019. Digitale transformation gestalten, digitale transformation gestalten. München: Carl Hanser Verlag GmbH \& Co.

Gebert-Persson, S., M. Gidhagen, J.E. Sallis, and H. Lundberg. 2019. Online insurance claims: When more than trust matters. International Journal of Bank Marketing 37 (2): 579-594.

Golia, N. 2018. Why the co-operators is exploring 'episodic' insurance. https://www.dig-in.com/news/ why-the-co-operators-is-exploring-episodic-insurance.

Gomes, C., Z. Jin, and H. Yang. 2021. Insurance fraud detection with unsupervised deep learning. Journal of Risk and Insurance 88 (3): 591-624.

Guillen, M., J.P. Nielsen, and A.M. Pérez-Marín. 2021. Near-miss telematics in motor insurance. Journal of Risk and Insurance 88 (3): 569-589. 
Henkel, M., T. Heck, and J. Göretz. 2018. Rewarding fitness tracking-the communication and promotion of health insurers' bonus programs and the use of self-tracking data. In Social computing and social media, technologies and analytics, ed. G. Meiselwitz, 28-49. Cham: Springer.

Hohl, M., M. Erny, and A. Zeier Röschmann. 2020. "Insurance On-Demand" Kurzzeit-Versicherungen: Empirische Untersuchung zu Bekanntheit und Interesse. Winterthur: ZHAW School of Mangement and Law.

Kano, N., N. Seraku, F. Takahashi, and Tsuji Shin-ichi. 1984. Attractive quality and must-be quality. Journal of the Japanese Society for Quality Control 14 (2): 39-48.

Keller, B. 2018. Virtual competition: Online platforms, consumer outcomes and competition in insurance. Geneva: The Geneva Association.

Köneke, V., H. Müller-Peters, and D. Fetchenhauer. 2015. Versicherungsbetrug verstehen und verhindern. Wiesbaden: Springer Fachmedien.

KPMG. 2017. Will on-demand insurance become mainstream? United Kingdom: KPMG.

Lamberti, F., V. Gatteschi, C. Demartini, M. Pelissier, A. Gomez, and V. Santamaria. 2018. Blockchains can work for car insurance: Using smart contracts and sensors to provide on-demand coverage. IEEE Consumer Electronics Magazine 7 (4): 72-81.

Landes, X. 2015. How fair is actuarial fairness? Journal of Business Ethics 128 (3): 519-533.

Lewis, S. 2017. Insurtech: an industry ripe for disruption. Georgetown Law Technology Review 491: 491-502.

Lin, X., and W.J. Kwon. 2020. Application of parametric insurance in principle-compliant and innovative ways. Risk Management and Insurance Review 23 (2): 121-150.

Ma, M.-Y., C.-W. Chen, and Y.-M. Chang. 2019. Using Kano model to differentiate between future vehicle-driving services. International Journal of Industrial Ergonomics 69: 142-152.

Martin, A. 2018. What is parametric insurance? https://corporatesolutions.swissre.com/insights/knowl edge/what_is_parametric_insurance.html.

Mazzini, J. 2021. Don't be fooled, Insurtech isn't a new thing. https://www.celent.com/insights/38564 7398.

McFall, L., and L. Moor. 2018. Who, or what, is insurtech personalizing?: persons, prices and the historical classifications of risk. Distinktion: Journal of Social Theory 19 (2): 193-213.

Miesler, L. and A. Bearth. 2016. "Willingness to share" im Kontext Big Data: Wie entscheiden Kunden, ob sie ihre persönlichen Daten mit Unternehmen teilen? In Dialogmarketing Perspektiven 2015/2016, 49-66. Wiesbaden: Springer Fachmedien.

Miyazaki, H. 1977. The rat race and internal labor markets. The Bell Journal of Economics 8 (2): 394.

National Association of Insurance Commissioners. 2021. On-Demand Insurance, NAIC.

Nickerson, R.C., U. Varshney, and J. Muntermann. 2012. A method for taxonomy development and its application in information systems. European Journal of Information Systems 22 (3): 336-359.

Osterwalder, A., Y. Pigneur, and C.L. Tucci. 2005. Clarifying business models: origins, present, and future of the concept. Communications of the Association for Information Systems 16 (1): 1-25.

Pousttchi, K., and A. Gleiss. 2019. Surrounded by middlemen-how multi-sided platforms change the insurance industry. Electronic Markets 29 (4): 609-629.

Pugnetti, C., and S. Elmer. 2020. Self-assessment of driving style and the willingness to share personal information. Journal of Risk and Financial Management 13 (3): 53.

Pugnetti, C., and M. Seitz. 2021. Data-driven services in insurance: potential evolution and impact in the Swiss market. Journal of Risk and Financial Management 14 (5): 227.

Rejda, G.E., and M.J. McNamara. 2017. Principles of Risk Management and Insurance. Harlow: Pearson.

Riasanow, T. 2020. Digital transformation from an inter-organizational perspective: managing the coevolution of platform owners and complementors in platform ecosystems. Dissertation, Technische Universität München.

Roberts, N.F., D.P. Peterson, and T. Konstantopoulos. 2020. InsurTech and the disruption of the insurance industry. Journal of Insurance Issues 43 (2): 64-96.

Sawers, P. 2017. Insurance startup sure raises $1 \$ 8$ million and launches smartphone protection based on virtual diagnostics. https://venturebeat.com/2017/06/14/insurance-startup-sure-raises-8-million/.

Schmeiser, H. 2018. Deckung auf Knopfdruck. Handelszeitung, July.

Spence, M. 1978. Product differentiation and performance in insurance markets. Journal of Public Economics 10 (3): 427-447.

Stanczyk, M. 2018. Push the button. Versicherungswirtschaft, August.

Stöckli, E., C. Dremel, F. Uebernickel, and W. Brenner. 2019. Auswirkungen von InsurTech auf die Wertschöpfungslogik der Versicherungsindustrie im Digitalen Zeitalter. In Digitale Geschäftsmodelle -, vol. 2, ed. S. Meinhardt and A. Plaum, 197-212. Wiesbaden: Springer Vieweg. 
Stoeckli, E., C. Dremel, and F. Uebernickel. 2018. Exploring characteristics and transformational capabilities of InsurTech innovations to understand insurance value creation in a digital world. Electronic Markets 28 (3): 287-305.

Störmer, T. 2015. Optimizing insurance pricing by incorporating consumers' perceptions of risk classification. Zeitschrift für die gesamte Versicherungswissenschaft 104 (1): 11-37.

Tata Consultancy Services. 2019. On-demand insurance: challenges and opportunities for large insurance carriers. India: Tata Consultancy Services Ltd.

Teece, D.J. 2010. Business models, business strategy and innovation. Long Range Planning 43 (2-3): 172-194.

Veit, D., E. Clemons, A. Benlian, P. Buxmann, T. Hess, D. Kundisch, J.M. Leimeister, P. Loos, and M. Spann. 2014. Business models, business \& information. Systems Engineering 6 (1): 45-53.

Vereinigung der Bayerischen Wirtschaft. 2017. Digitalisierung in der Versicherungswirtschaft. München: Vereinigung der Bayerischen Wirtschaft e.V.

Wagner, F. 2017. Gabler Versicherungslexikon. Wiesbaden: Springer Fachmedien.

Weber, T.A. 2014. Intermediation in a sharing economy: insurance, moral hazard, and rent extraction. Journal of Management Information Systems 31 (3): 35-71.

Weidner, W., F.W. Transchel, and R. Weidner. 2017. Telematic driving profile classification in car insurance pricing. Annals of Actuarial Science 11 (2): 213-236.

Wiegard, R.-B., and M.H. Breitner. 2019. Smart services in healthcare: a risk-benefit-analysis of pay-asyou-live services from customer perspective in Germany. Electronic Markets 29 (1): 107-123.

Wilson, C. 1977. A model of insurance markets with incomplete information. Journal of Economic Theory 16 (2): 167-207.

Wüthrich, M.V. 2017. Covariate selection from telematics car driving data. European Actuarial Journal 7 (1): 89-108.

Zott, C., R. Amit, and L. Massa. 2011. The business model: recent developments and future research. Journal of Management 37 (4): 1019-1042.

Zwack, T., H. Habicht, and V. Lüdemann. 2016. Peer-to-Peer-Absicherung privater Risiken: Eine Exploration am Beispiel von Wildschaden. Zeitschrift für die gesamte Versicherungswissenschaft 105 (4): $325-353$.

Zweifel, P., and R. Eisen. 2012. Insurance economics springer texts in business and economics. Berlin, Heidelberg: Springer.

Publisher's Note Springer Nature remains neutral with regard to jurisdictional claims in published maps and institutional affiliations.

\section{About the authors}

Angela Zeier Röschmann is a Professor at the Institute for Risk \& Insurance at the ZHAW School of Management and Law. Her research focus is on new business models in insurance and governing risk. She holds a PhD in Management from the University of St. Gallen, ARM from the Institutes and an MBA from the California State University Northridge.

Matthias Erny is a lecturer at the Institute for Risk \& Insurance at the ZHAW School of Management and Law. His research focuses on new business models, transformation and decision-making processes in life and non-life business. He holds a PhD in Social Sciences form the University of St. Gallen.

Joël Wagner is a Full Professor in the Department of Actuarial Science at the Faculty of Business and Economics (HEC) of the University of Lausanne and Faculty Member of the Swiss Finance Institute. Before, he was a consultant at the Boston Consulting Group and an Assistant Professor at the University of St. Gallen. He holds a PhD in Mathematics and an engineering degree in Physics from the Swiss Federal Institute of Technology in Lausanne. His research includes topics in risk management and insurance. 


\section{Authors and Affiliations}

\section{Angela Zeier Röschmann ${ }^{1}$ (D) Matthias Erny ${ }^{1} \cdot$ Joël Wagner $^{2,3}$ (iD}

Angela Zeier Röschmann

angela.zeierroeschmann@zhaw.ch

Matthias Erny

matthias.erny@zhaw.ch

1 Institute for Risk \& Insurance, ZHAW School of Management and Law, Technoparkstrasse 2, 8400 Winterthur, Switzerland

2 Department of Actuarial Science, Faculty HEC, University of Lausanne, Chamberonne Extranef, 1015 Lausanne, Switzerland

3 Swiss Finance Institute, University of Lausanne, 1015 Lausanne, Switzerland 